\title{
A review of Product-Service Systems Design Methodologies
}

\author{
Gokula Vijaykumar A.V. ${ }^{1 *}$ and Rajkumar Roy ${ }^{2}$ \\ Department of Manufacturing \\ Cranfield University \\ MK43 0AL, UK \\ 1* g.v.annamalaivasantha@cranfield.ac.uk \\ 2 r.roy@cranfield.ac.uk \\ Tel: +44 (0)1234758376
}

\author{
Alan Lelah ${ }^{1}$ and Daniel Brissaud ${ }^{2}$ \\ G-SCOP Laboratory, \\ University of Grenoble \\ Grenoble, France \\ 1 alan.lelah@g-scop.grenoble-inp.fr \\ 2 daniel.brissaud@inpg.fr \\ Tel: +33 (0) 476827006
}

\footnotetext{
${ }^{1}$ Research Fellow, ${ }^{2}$ Professor

* Corresponding author
}

Cite this article as:

Vasantha, G. V. A., Roy, R., Lelah, A., \& Brissaud, D. (2012). A review of product-service systems design methodologies. Journal of Engineering Design, 23(9), 635-659. 


\begin{abstract}
Product-Service Systems (PSS), motivated to fulfil customers' needs, are seen as good strategies to face today's competitive business environment. The field of PSS research is however not fully mature and many different methodologies are proposed for PSS design. This paper seeks to understand the directions taken in eight state-of-the-art methodologies so as to identify common needs in future research. The methodologies are studied across their authors' views and definitions of services, PSS and their objectives and challenges, along with the tools that have been developed. A maturity model is built to access current PSS design across 20 dimensions. The model highlights that only three dimensions are strongly treated: design processes for integrating products and services, definitions of new terminologies and considerations concerning planning and designing lifecycle phases. To enhance the industrial application, collaboration between researchers and practitioners can be spurred through two challenges: common ontology and models for representation of PSS. Particular attention must also be placed on sustainability as current models do not support the generation of sustainable PSS. As a whole, the review shows that the PSS design is still in initial stages of development and substantial research is required to develop a practical PSS design methodology.
\end{abstract}

Keywords: Product-Service Systems, Design Methodologies, Ontology, Sustainability, Survey 


\section{Introduction}

Globalization and increasing demands from customers pose a challenge to industry and prompt it to become more sustainable. These challenges have been magnified with the recent economic crisis and they force industry to explore strategies to gain leverage. One potential strategy is the shift from a product- to a service-based economy. In a service based economy, satisfying individualised customer needs play a vital role rather than focusing on mass-production and consumption. Customers are more interested in availability or capability rather than purchasing physical artefacts (Ministry of Defence, 2005). The benefits derived from improved availability are mutual for manufacturers and customers. Traditional offerings are no longer valid in this scenario in terms of risk and uncertainty.

Within this context, manufacturers can add value by including various services within their offerings. This change is commonly termed as servitization. This transformation has emerged essentially due to decreasing demands for products that become less attractive and from lower profits gained from selling products. The main advantage in the industrial domain is to lock the customer into a long-term relationship (Vandermerwe, 2000). To build a sustainable relationship in a competitive and challenging environment, manufacturers should create enough confidence for the customers and undertake and manage the larger risks and uncertainties ( $\mathrm{Ng}$ and $\mathrm{Nip}, 2009)$. This transformation provides other advantages like the difficulty for competitors to imitate the service and improved knowledge through better insight of product use (Alonso-Rasgado et al., 2004). Various similar concepts have been proposed in literature such as 'functional sales', 'integrated solutions' and 'soft products'.

In servitization, product-service systems (PSS) form a special case. A PSS is an integrated product and service offering that delivers value in use to the customer (Baines et al., 2007). Meier et al. (2010) provided a wider insight of research scenarios across the PSS research areas. They argued that PSS enable innovative function-, availability- or result-oriented business models. The aim of PSS is to value asset performance rather than ownership and differentiation through the integration of products and services (Baines et al. 2007). Meier and Massberg, (2004) added the idea that PSS provide solutions that integrate products, services and business models.

In the process of transformation towards PSS, industries require support in terms of tools, techniques and methods. They need assistance to develop systems ready to deliver offerings over prolonged periods of time. In literature some methodologies have been proposed to support them. Even though their intentions are similar, the proposed methodologies differ in objectives, scope and the elements used. These differences need to be highlighted in order to understand and choose the appropriate method. The goal of this paper is to harmonise all the different points they treat and point out the opportunities to improve the state of art.

In this review, 8 well-represented methodologies from literature have been selected. Similarities and differences between them are discussed regarding the definition of service and PSS and the objectives pursued. An in-depth analysis of their proposed tools and methods as well as their respective merits and demerits is then undertaken. A maturity model illustrating the current state of the art is identified. Following this, the review discusses three major challenges facing PSS today: the development of ontology; systematic modelling approaches emphasizing co-creation; and sustainability issues. The paper concludes with a summary of research gaps and proposes future directions of research to design productservice systems. 


\section{PSS research methodology and fundamentals}

\subsection{Review of selected methodologies}

In this paper, state of the art methodologies proposed for PSS design are reviewed in-detail. Since in-depth analysis is the main aim of this paper, only methodologies proposed specifically in the PSS domain have been considered. Other product or service design methodologies are not discussed here. We have decided to focus on eight state of the art PSS design methodologies. The criteria for choosing these models can be summarized:

- The methodology should have been detailed rather than described with general models.

- The methodology should have been applied and demonstrated through industrial examples.

- The methodologies should be published in referred journals and adequately cited in literature.

- The methodologies should be applicable in business to business environments where developing products and services are complex and influenced by many factors.

Considering these criteria, the authors of this paper have selected these eight methodologies for study. It was decided to restrict to only eight methodologies in order to avoid loss of focus and not to overcharge the study. The methodologies selected are sufficiently detailed and mature and as well as being highly referred to within the PSS community. Table 1 details the methodologies chosen resuming their approach, a brief description and the references explored in the analysis.

Table 1 Details of methodologies chosen for in-depth analyses

\begin{tabular}{|c|c|c|}
\hline Approach & Description & References \\
\hline Service CAD & $\begin{array}{l}\text { A method to design business models that increase eco- } \\
\text { efficiency from a systemic perspective. }\end{array}$ & $\begin{array}{l}\text { Tomiyama, 2001; Komoto } \\
\text { and Tomiyama, 2008, 2009; } \\
\text { Komoto, 2009; }\end{array}$ \\
\hline $\begin{array}{l}\text { Service Model } \\
\text { Service Explorer }\end{array}$ & $\begin{array}{l}\text { Focuses on service engineering to design products with } \\
\text { a higher added-value from enhanced services. }\end{array}$ & $\begin{array}{l}\text { Sakao and Shimomura, 2007; } \\
\text { Shimomura et al. 2008, 2009; } \\
\text { Sakao et al. 2009; Kimita et } \\
\text { al. 2009; Hara et al. 2009. }\end{array}$ \\
\hline $\begin{array}{l}\text { Integrated product and service } \\
\text { design processes }\end{array}$ & $\begin{array}{l}\text { Exploits the potential of interrelations between } \\
\text { physical products and non-physical services and the } \\
\text { development of corresponding design processes. }\end{array}$ & Aurich et al. 2006a and b. \\
\hline $\begin{array}{l}\text { Fast-track Total Care design } \\
\text { process }\end{array}$ & $\begin{array}{l}\text { Develops innovative offerings consisting of hardware } \\
\text { and services integrated to provide complete functional } \\
\text { performance. }\end{array}$ & $\begin{array}{l}\text { Alonso-Rasgado et al., 2004; } \\
\text { Alonso-Rasgado and } \\
\text { Thompson, } 2006 .\end{array}$ \\
\hline PSS Design & $\begin{array}{l}\text { Assists engineers in the joint development of physical } \\
\text { products and interacting services to generate more } \\
\text { added value. }\end{array}$ & Maussang et al. 2009. \\
\hline $\begin{array}{l}\text { Heterogeneous IPS }{ }^{2} \text { concept } \\
\text { modelling }\end{array}$ & $\begin{array}{l}\text { A model based approach of diffuse borders between } \\
\text { products and services that generates heterogeneous } \\
\text { Industrial Product-Service Systems (IPS }{ }^{2} \text { ) concept }\end{array}$ & $\begin{array}{l}\text { Meier and Massberg, 2004; } \\
\text { Welp et al. 2008; Sadek and } \\
\text { Theiss, } 2010 .\end{array}$ \\
\hline
\end{tabular}




\begin{tabular}{|c|c|c|}
\hline & models in the early phase of IPS ${ }^{2}$ development. & \\
\hline $\begin{array}{l}\text { The dimensions of PSS } \\
\text { Design }\end{array}$ & $\begin{array}{l}\text { A comprehensive description of PSSs capable of } \\
\text { generating new PSS concepts. }\end{array}$ & Tan et al. 2009, 2010. \\
\hline $\begin{array}{l}\text { The design process for the } \\
\text { development of an integrated } \\
\text { solution }\end{array}$ & $\begin{array}{l}\text { Development of methodological tools to support } \\
\text { designers and generate systemic solutions including } \\
\text { products and services. }\end{array}$ & Morelli 2002, 2006. \\
\hline
\end{tabular}

Other methods that did not fulfil all criteria but that show interesting potential in developing PSS are cited. Bullinger et al. (2003) proposed methods to systematise the development of services and discuss transferring product development experience into the service sector. Weber et al. (2004) introduce the concept of Property-Driven Design/Development (PDD) to develop a methodology for developing PSSs. The MEPSS methodology structures steps for designing PSS through strategic analysis, exploration of opportunities, PSS idea development, PSS concept design, and PSS project development and implementation (van Halen et al., 2005). Luczak et al. (2007) presented an architecture that comprises of steps to be taken to design and develop professional services. Ueda et al. (2008) proposed a value-creation model based on the concept of emergent synthesis. Rexfelt and Ornäs (2009) identified characteristics of PSS solutions likely to influence acceptance, and proposed procedures for conceptual development of PSS based on methodology adapted from user-centred design. Müller et al. (2009) proposed a PSS Layer Method for the development of Product-Service Systems (PSS) through nine classes: lifecycle activities, needs, values, deliverables, actors, core products, peripheries, contracts and finance. Even though these papers are not considered during the in-depth analyses, they provide a rich understanding of the topic and aid our analyses by targeting specific aspects to be considered in designing PSS.

\subsection{Definitions and main aspects of PSS}

The starting point in PSS methodologies depends on the definition of the terms 'service' and 'PSS'. There are many definitions for services and PSS in literature. In this paper we have only reviewed those proposed within the selected PSS methodologies in order to identify similarities.

\subsubsection{Services}

Tomiyama (2004) defined a service as a set of activities that delivers service contents through service channels from service providers to service receivers in a service environment, and generates values for service receivers.

Sakao and Shimomura (2007) and Shimomura et al. (2009) defined services identically. A service is an activity where a provider causes a receiver, usually with consideration, to change from an existing state to a new state that the receiver desires, where both contents and a channel are means to realize the service; while a traditional service performed only by a human is called "service activity".

Aurich et al. (2006) argued that technical services are mainly non-physical and are realized and consumed simultaneously. They classified three basic technical service functions: support function, requirements fulfilment and information procurement. 
Maussang et al. (2009) stressed that the physical objects are functional entities that carry out the elementary functions of the system, while the service units are entities (mainly technical) that will ensure the smooth functioning of the whole system.

Alonso-Rasgado et al. (2004) pointed out that the functional product supplier provides all the support systems that are required to keep the hardware operable. The support systems are often referred to as 'services'.

Welp et al. (2008) argued that industrial services have evolved from being a peripheral add-on for technology to become a complementary part of an integral solution. Services exhibit a high degree of intangibility.

Even though differences are clearly perceptible between the definitions, they are all relevant in the context of PSS. From these definitions, two different views exist to define service. They can be classified by the 'traditional' and 'broader' perspectives taken. In the traditional approach, a service is a set of activities which intends to keep products functionally available. Such services can be maintenance, repair, overhaul, upgrade or other technical services. In a broader perspective, a service is a set of activities which intends to satisfy customer value. Both views are possible depending on the context of the application. If the product is already matured then the traditional perspective is usually more appropriate. If the product is in the early stages of development then the broader approach offers more advantages. Defining properties of service vary according to the perspective chosen. Service properties such as intangibility, heterogeneity, inseparability, perishability, concretization and simultaneous consumption are suitable in the traditional approach. However properties seen from a broader perspective are not defined. The emphasis of the process of co-creation is more adapted to the broader approach because of the search for global value. Broader approaches provide wider contexts for considering environmental influences and substitution between tangible and intangible objects. The different stages of service, such as creation, delivery and utilization could be commonly used in both approaches. Evaluation criteria for services vary between approaches. Criteria such as user experiences and expectations are emphasised in the broader perspective whereas uptime, failure rate and severity of failures are primarily emphasised in the traditional approach. Table 2 summarizes the differences identified above. The PSS design methodologies reviewed in the next section will be referenced to these elements.

Table 2 Service definition variations through two approaches

\begin{tabular}{|c|c|c|}
\hline Characteristics & Traditional Approach & Broader Approach \\
\hline Primary objective & $\begin{array}{c}\text { Functionally available product. Fit for } \\
\text { use. }\end{array}$ & Satisfaction of customer value. \\
\hline Applicability & Matured product & $\begin{array}{c}\text { Initial stages of development } \\
\text { define concretely. }\end{array}$ \\
\hline Properties & $\begin{array}{c}\text { Intangible, heterogeneous, inseparable, } \\
\text { perishable, realized and consumed } \\
\text { simultaneously }\end{array}$ & $\begin{array}{c}\text { Derived from customer value. Yet to } \\
\text { primarily. }\end{array}$ \\
\hline Stakeholders Involvement & $\begin{array}{c}\text { Co-operation in terms of information } \\
\text { transfer and usage analyses. }\end{array}$ \\
\hline Degree of freedom & Restricted and focused to operational \\
& factors. & $\begin{array}{c}\text { Wider scope with opportunities to } \\
\text { substitute between tangible and }\end{array}$ \\
\hline
\end{tabular}




\begin{tabular}{|c|c|c|}
\hline & & intangible objects. \\
\hline Evaluation criteria & $\begin{array}{c}\text { Uptime, failure rate and severity of } \\
\text { failures }\end{array}$ & User experiences and expectations. \\
\hline
\end{tabular}

\subsubsection{PSS}

Various definitions of PSS were detailed in Baines et al. (2007). The definitions found in the PSS design methodologies studied in this paper are detailed and discussed here.

Komoto and Tomiyama (2009) have argued that the PSS concept has been proposed as a methodology to design innovative business models from economic, environmental and socio-cultural perspectives. A business model designed according to PSS concepts is referred to as PSS and the design process as PSS design process.

Sakao and Shimomura (2007) and Shimomura et al. (2009) defined Service/Product Engineering (SPE) as a discipline seeking to increase the value of artifacts by focusing on service. SPE aims at intensifying, improving, and automating the entire framework of service creation, delivery, and consumption.

Aurich et al. (2006a) argued that PSSs consist of mutually interrelated physical and non physical components. PSS methodology is the integration of product and service design processes.

Welp et al. (2008) characterised Industrial Product-Service Systems (IPS 2 ) by the integration of investment goods (technical products) and industrial services along their entire lifecycle.

Maussang et al. (2009) argued that PSSs are composed of physical objects and service units that relate to each other.

Alonso-Rasgado et al. (2004) defined Total Care Products (Functional Products) as integrated systems comprising hardware and support services.

Morelli (2002) has referred to PSS definitions using different perspectives:

- From a traditional marketing perspective the notion of PSS originates from a shift of focus from marketing products to a more complex combination of products and services which support production and consumption (Manzini, 1993).

- From a service marketing perspective, a PSS represents an evolution of traditional generic and standardized services towards targeted and personalized ones (Albrecht and Zemke, 1985).

- From a product management perspective, the notion of PSS refers to the extension of the service component around the product for business activities that are traditionally product-oriented or the introduction of a new service component marketed as a product for business activities that are usually service-oriented (Mont, 2000).

Tan et al. (2009) have defined PSS as shift in business strategy from a product-oriented to a serviceoriented focus, where instead of the product itself, the activity, its utility and performance associated with the use of the product are considered to be of more value to the customer. 
From these PSS definitions, three different themes emerge, namely the development of innovative business models, the integration of products and services into a unique offer and extending services to increase the value realization of products. These observations show that PSS design should focus on integrating business models, products and services together throughout the lifecycle stages, creating innovative value addition for the system. A comparison of the service factors discussed in Table 1 with the PSS definitions shows that innovation and added value will emerge by considering stakeholder involvement, degrees of freedom and evaluation criteria. Figure 1 depicts the elements involved in PSS. The next section emphasizes challenges and requirements for the development of PSS design methodologies.

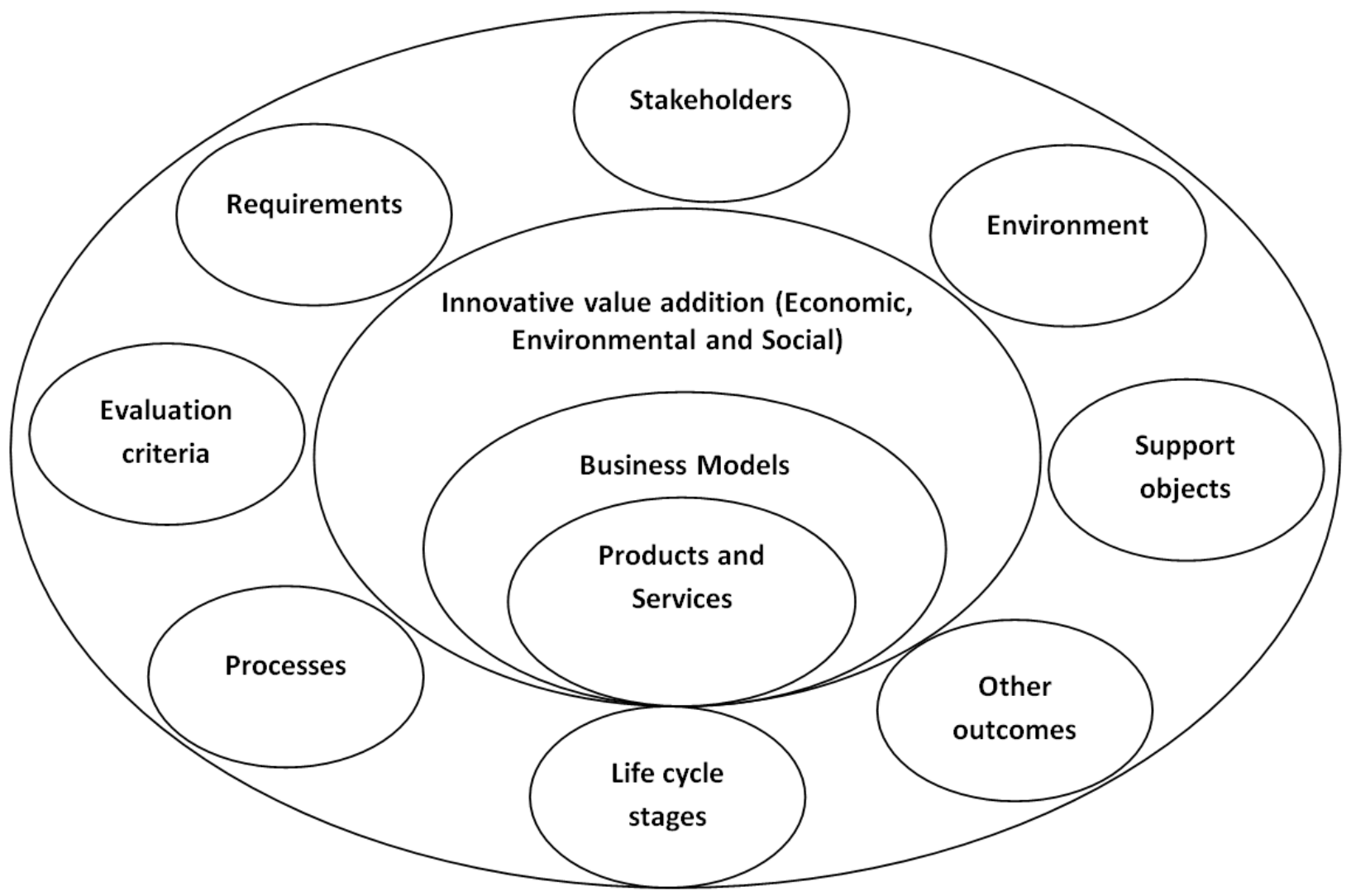

Figure 1 Elements involved in the PSS

\subsection{Primary issues in PSS design methodologies}

The challenges observed by the authors of the chosen methodologies in the development of PSS design are summarized and discussed in this section. These observations are important because they lay the foundation for further development of the methodologies.

Komoto and Tomiyama (2009) observed that theories and methodologies for PSS are weak and too general. There are multiple interpretations of the term 'service'. Quantitative and probabilistic evaluation of PSS offerings considering uncertainty throughout the product life cycle during conceptual design and emphasizing the behaviour of individual products are missing. Mont (2002) argued that there are many fragmented PSS solutions, but few are fully designed from a life cycle perspective. The importance of 
representation of PSS was stressed by Sakao and Shimomura (2007). They argued that service blueprint lacks representation of design information and has insufficient normative notation. They have pointed out the separation between the design of functions and those of service activities.

Aurich et al. (2006) highlighted the insufficient consideration of mutual influences of products and technical services in service design that is frequently detached from product design. They have stressed that unavailability or unimplemented service design processes frequently results in unnecessary cost on an operational level when responding to changing customer demands. Welp et al. (2008) have observed that there are currently no integrated, model-based approaches available that support PSS designers to generate PSS concepts. They plead for methods that integrate stakeholder's preferences in determining PSS artefacts. Most of the authors commonly asserted that identifying and differentiating products and services in modelling is a challenge.

Maussang et al. (2009) stressed the importance of specifying engineering product criteria in defining PSS. They argued that the role of designers during PSS design is quite different from the development of conventional products. They observed that no compromises between physical objects and services are effective since these choices are made a posteriori to product development. Alonso-Rasgado et al. (2004) pointed that modelling the proposed service system seems to receive little attention. They particularly emphasized the inability to accurately portray human behaviour to describe services. Many issues identified in literature together with low similarities stressed that the field of PSS design methodologies is not mature.

The following points summarize the issues that need to be addressed in methodologies to generate and evaluate PSS design.

- Identification of the requirements of stakeholders involved in the PSS including preferences and change over time.

- An aid to understanding and identifying influences, compromises and differences between products and services throughout their lifecycle.

- A process for developing integrated solutions for products and services that considers the overall functionality to be delivered.

- A good schema for representing PSS concepts with appropriate notation that avoids misinterpretation.

- A comprehensive evaluation of developed PSS concepts that considers individualistic product and service behaviour to identify implications such as uncertainty and risks for through life of offering period.

Even though it has not been highlighted in literature, significantly, the definition of PSS designers is rather vague. Responsibilities of PSS designers in the context of the organization should be specified and established. Moreover, some of the challenges involved in developing business models are mentioned in the chosen methodologies, but generally, more detailed identification and representation of business issues need to be incorporated. Addressing these issues should help develop design theory and methodologies that contribute to the creation of adaptable PSS concepts more systematically. 


\subsection{Derivation of required dimensions to develop PSS}

From the review of Sections 2.1, 2.2 and 2.3, and from our understanding of PSS literature, the dimensions required to develop effective PSS can be grouped into six categories: context specification; positioning and importance of stakeholders; design stages; development cycle; life cycle consideration; and representation. Issues underlying these dimensions are detailed below.

- Context specification

1. Maturity of the product and consideration of the industrial domain (Business to Customer, Business to Business and Business to Government)

- Positioning and importance of stakeholders

2. Identification of requirements and preferences

3. Specification of roles and capabilities

4. Structuring the co-creation process

- Design stages

5. The design process for the integration of products and services

6. The design process for creating business models

7. Influences of business models on the integrated solutions

8. Incorporation of multi-disciplinary approaches

9. Specification of differences in the design process for different types of PSS (e.g. product-, use- and result-oriented)

10. Focus on sustainable development

- Development cycle

11. Generation process

12. Evaluation process

- Life cycle considerations

13. Planning and design phases

14. Implementation and monitoring phases

15. Feedback loops between phases

- Representation rigour

16. Representation techniques

17. Levels of granularity considered

18. Definition of elements

19. Specification of quantitative and qualitative factors

20. Dynamics involved

With these twenty points, the set of eight chosen methodologies have been analysed and a maturity model has been derived. The following section discusses the frame of objectives and the elements used to represent PSS along with the tools and methods proposed by the authors. 


\section{Analysis of 8 methodologies found in literature and proposal of a maturity model for PSS design research}

\subsection{Analysis grid}

The eight selected methodologies in Table 1 were analysed to examine their contributions to the twenty dimensions identified in section 2.4. The objective was to provide a state of the art review of current areas under focus and identify notable gaps. For this, each group of authors was individually assigned a score going from 0 to 2 for each dimension. A score of 2 was attained when we found a discussion for that dimension. A score of one was given when the issue was simply mentioned but not discussed. Zero was assigned if the issue was not considered. The final score for the eight methodologies was then calculated and expressed as a percentage to facilitate comprehension. The score is based on information found in the papers studied and does not necessarily represent a fully accurate idea of the reflection of the proposed authors but should give a reasonable indication of what issues are relatively well treated in literature today. The following sections briefly describe each methodology and discuss the maturity model. The scores of the twenty dimensions are represented in the maturity diagram (Figure 10).

\subsection{Literature proposed methods/tools}

Komoto and Tomiyama $(2008,2009)$ aimed to improve the PSS design process with systematic information on creation supported by computational facilities. They proposed Service CAD to help designers generate a conceptual design of PSSs. It systematically supports designer decision making regarding design problems by evaluating the design concepts and suggesting alternatives to improve them. They argued that in the PSS design processes, designers define the activity to meet specified goals and quality, and define the environment in which the activity takes place. The elements used in Service CAD are the service environment, provider, receiver, channel, content, activity, receiver's intention, target, promised goal, realised service, quality and value added. Figure 2 details the architecture of Service CAD. They also developed ISCL (Integrating Service CAD with a life cycle simulator) which has functions to support quantitative and probabilistic PSS design using life cycle simulation. The quality descriptions in a PSS model are the parameter values of constituents and the number of constituents in a market. Probabilistic descriptions are included in the conditions and consequences of executing activities.

Komoto and Tomiyama $(2008,2009)$ argued that their model can be used as a meta-level representation in which the designer can construct a PSS model in different views (aspects) such as process-oriented (e.g. using service blueprinting), stakeholder-oriented (system map) and correspondence-oriented (Serviset). Importantly, products in a business model are individual instances rather than assuming that all products have identical behaviour in the market and end of life processes. They also expressed the difficulty for designers to categorize elements as provider, receiver, channel or content. The important limits they found in Service CAD come from: monotonically increasing and decreasing functions; unrelated results of evaluations of multiple sequences of activities that partially overlap; incapacity to identify conflictive objectives among multiple stakeholders in a PSS model; and difficulty to optimize timing, frequency and interrelations of services within the PSS model. 


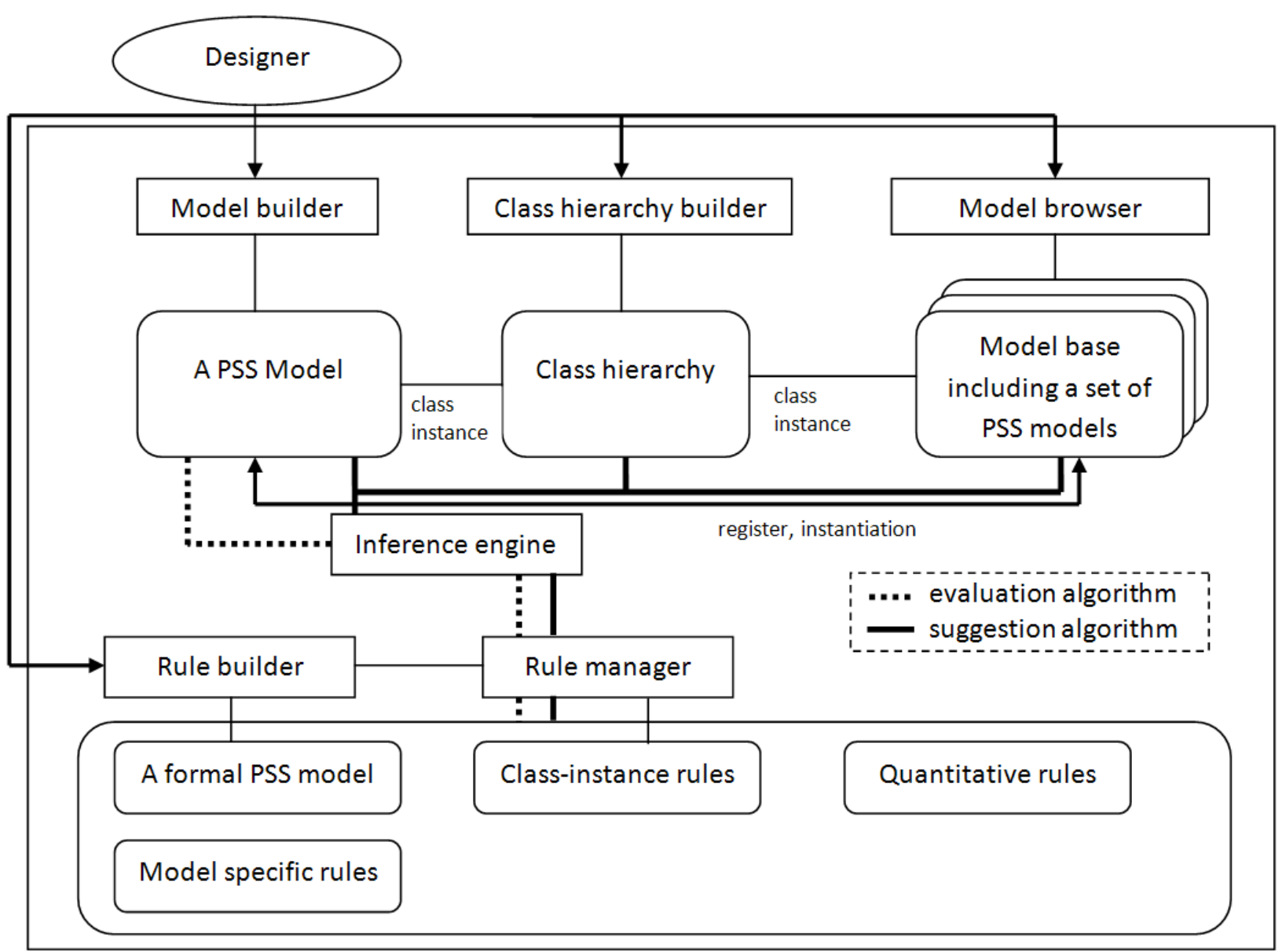

Figure 2 The architecture of Service CAD (Komoto and Tomiyama, 2009)

Shimomura et al. (2009) proposed a method for designing service activity and products concurrently and collaboratively during the early phase of product design. They argued that the design of services and products should be integrated in order to maximize customer value, considering mutual effects of synergy, alternatives and complementarities. They proposed a unified representation scheme of human and physical processes in service activity. They expressed the change of state for a customer through Receiver State Parameters (RSPs), which represent customer value. They proposed a view model to handle functions and attributes to represent RSPs. They argued that the lowest-level functions are associated with real entities such as hardware, humans and software. They extended service blueprinting to include physical processes to connect with view models representing service content and employed the Business Process Modelling Notation (BPMN). They included three phases in service design processes: identifying customer value, design of service contents and design of service activity. They also developed a method to evaluate these processes with Quality Function Deployment (QFD). Sakao et al. (2009) developed a service model consisting of four sub-models: 'flow model (who)', 'scope model (what)', 'scenario model (why)', and 'view model (how)' (Figure 3). They developed and implemented these models in a prototype system called Service Explorer. 


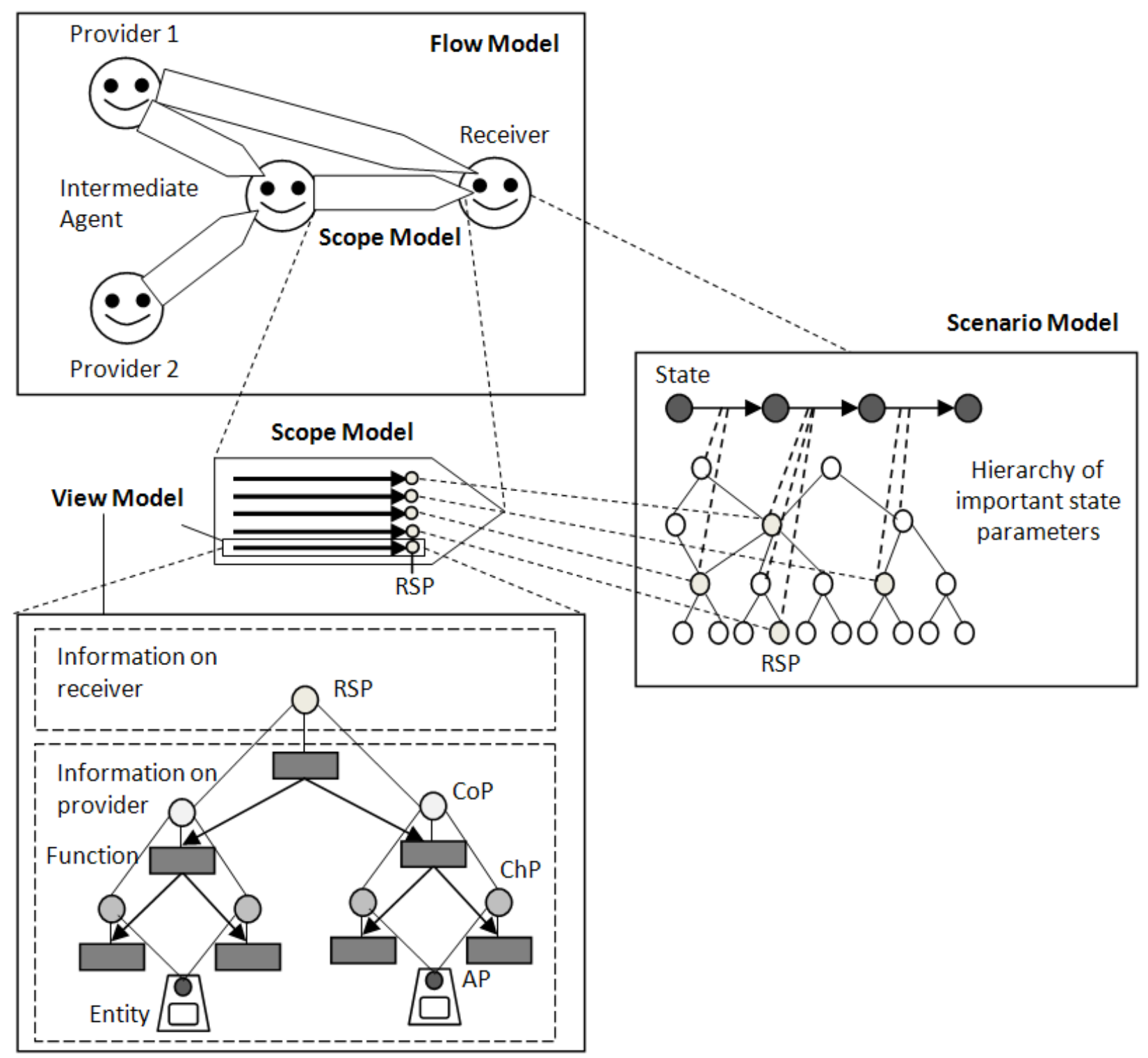

Figure 3 Relations between the sub-models: flow, scope, scenario and view models (Sakao et al. 2009)

Sakao and Shimomura (2007) argued that their method identified the roles of products in the entire service by integrating the extended blueprint and the view models, which are constructed independently and linked mutually. They stated that future research includes a simulation tool which enables service designers to predict service availability based on the proposed extended service blueprint. A synthesised process with Service Explorer has to be developed because the selection of contents and channels is subjective. It was argued that Service Explorer could not evaluate specific activities that dynamically maintain and improve activity, content and channel parameters, which finally influence RSPs.

Aurich et al. (2006a) introduced a process for the systematic design of product-related technical-services based on modularization that links with the corresponding product design process. They illustrated three different kinds of product service strategies: liability-driven, function-driven and use-driven. Their approach to systematic development of integrated product and service design processes is illustrated in 
Figure 4. It illustrates the general product and service design process. They proposed an object-oriented technical-service model to support the specification of technical services during design. They used the Unified Modelling Language (UML 2.0) for representation. They suggested that adapting already existing product design processes to account for the special characteristics of technical services would lead to greater acceptance for application within the enterprise. They argued that modular reference process models help develop common understanding of all the involved entities concerning design and manufacturing and help identify differences due to particular geographical or cultural backgrounds of the service partners and their different sizes or the demands specified by the customers. The technical service design process involves: identification of customer demand, feasibility analysis, concept development, service modelling, realization, planning and prototypical service testing.

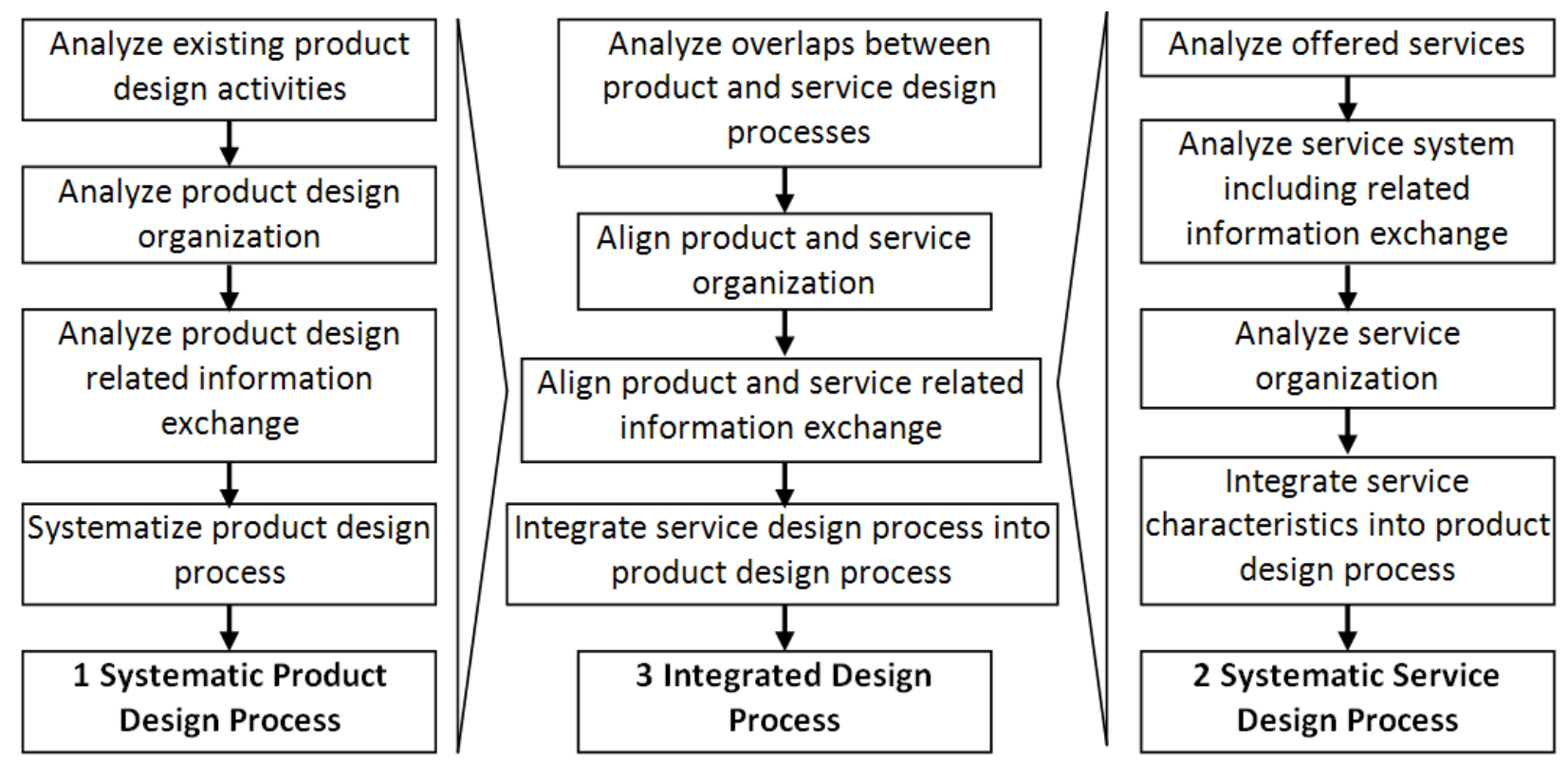

Figure 4 Integrated product and service design processes (Aurich et al. 2006)

Aurich et al. (2006a and b) noted the importance of extended value creation networks to face changing customer requirements flexibly. They claimed that highly individualized design processes are required to support the design of individual products, services and PSS. They argued that research is required on systematic investigation of the interrelations between products and technical services as well as on corresponding design activities.

Welp et al. (2008) argued that industrial PSS (IPS 2 ) considers any combination of product and service shares. They say that the IPS ${ }^{2}$ concept development is responsible for generating the principle solutions to meet specific customer requirements. They presented a model-based approach to support an IPS ${ }^{2}$ designer generating heterogeneous IPS ${ }^{2}$ concept models in the early phase of development. The proposed approach allows for the combination of multidisciplinary solution elements on arbitrary levels of abstraction from different development perspectives. The heterogeneous IPS ${ }^{2}$ concept modelling approach was implemented as a software prototype and was evaluated on a typical IPS ${ }^{2}$ issue. They represented a noun (IPS ${ }^{2}$ object) and a verb (IPS ${ }^{2}$ process) that constitute a function. The combination of 'IPS ${ }^{2}$ objects' and 'IPS ${ }^{2}$ processes' constitutes an 'IPS ${ }^{2}$ artefact' (Figure 5). They emphasized that the combination of IPS ${ }^{2}$ objects and IPS ${ }^{2}$ processes would generate functional behaviour. Heterogeneous modelling of an IPS ${ }^{2}$ 
concept was developed using three different types of model elements: i) system elements, ii) disturbance elements and iii) context elements. They defined five constitutive characteristics that form the basis to characterize IPS 2 artefacts: specificity; dominant transformation; scale of integration; capability for partial substitution of an IPS 2 artefact; and connectivity.

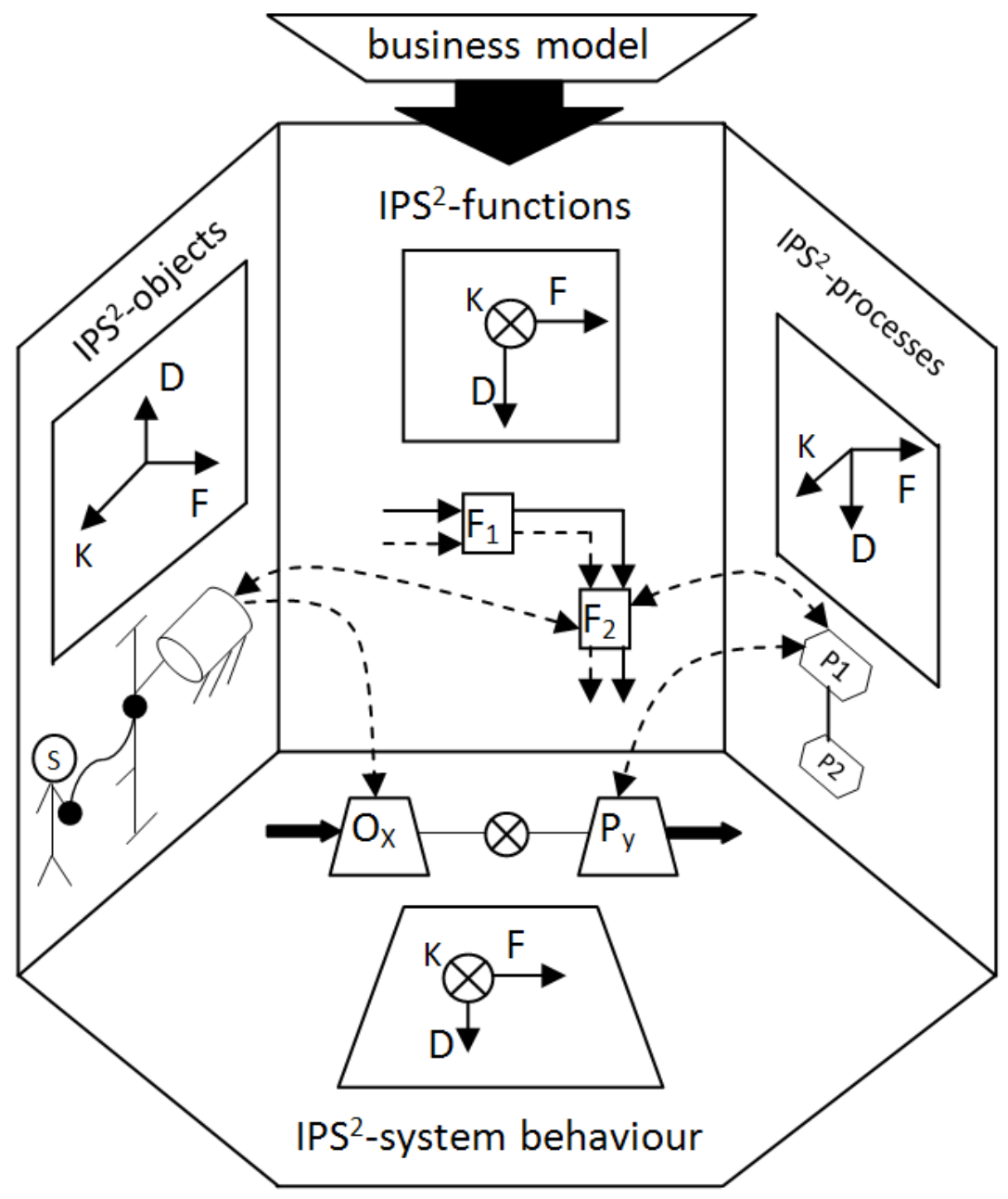

Figure 5 Structure of the extended heterogeneous IPS 2 concept modelling approach (Welp et al. 2008)

Welp et al. (2008) stressed the need for a combination of multidisciplinary solution elements. This means subsequent simulation to develop suitable solvers that determine the results of physical as well as process behaviour.

Maussang et al. (2009) developed a methodology to provide engineering designers with technical engineering specifications in relation to complete system requirements as precisely as possible. They focused not only on the design of physical objects, but rather considered the whole system and detailed the physical objects and service units necessary to develop a successful PSS. They argued that this methodology can support the design of PSSs starting from the design of the architecture down to detailed specification of physical objects (products). They used operational scenarios to go deeper into the description of the system once the main elements (physical objects and service units) had been identified 
(Figure 6). SADT representation was used to describe scenarios based on the description of activities. They used the functional analysis approach (AFNOR, 1991) to bridge the gap between the system approach and product development. They proposed to use these tools jointly with functional scenarios to design consistent PSS. They argued that a specific external analysis had to be carried out for each step of the product life cycle. They defined interaction functions, which correspond to functions provided by the product to an outer environment during the product life cycle and adaptation functions that reflect reactions, resistances or adaptations from the outer environment. They stressed that accessibility (economic and cognitive) and service availability are the two main elements of the PSS.

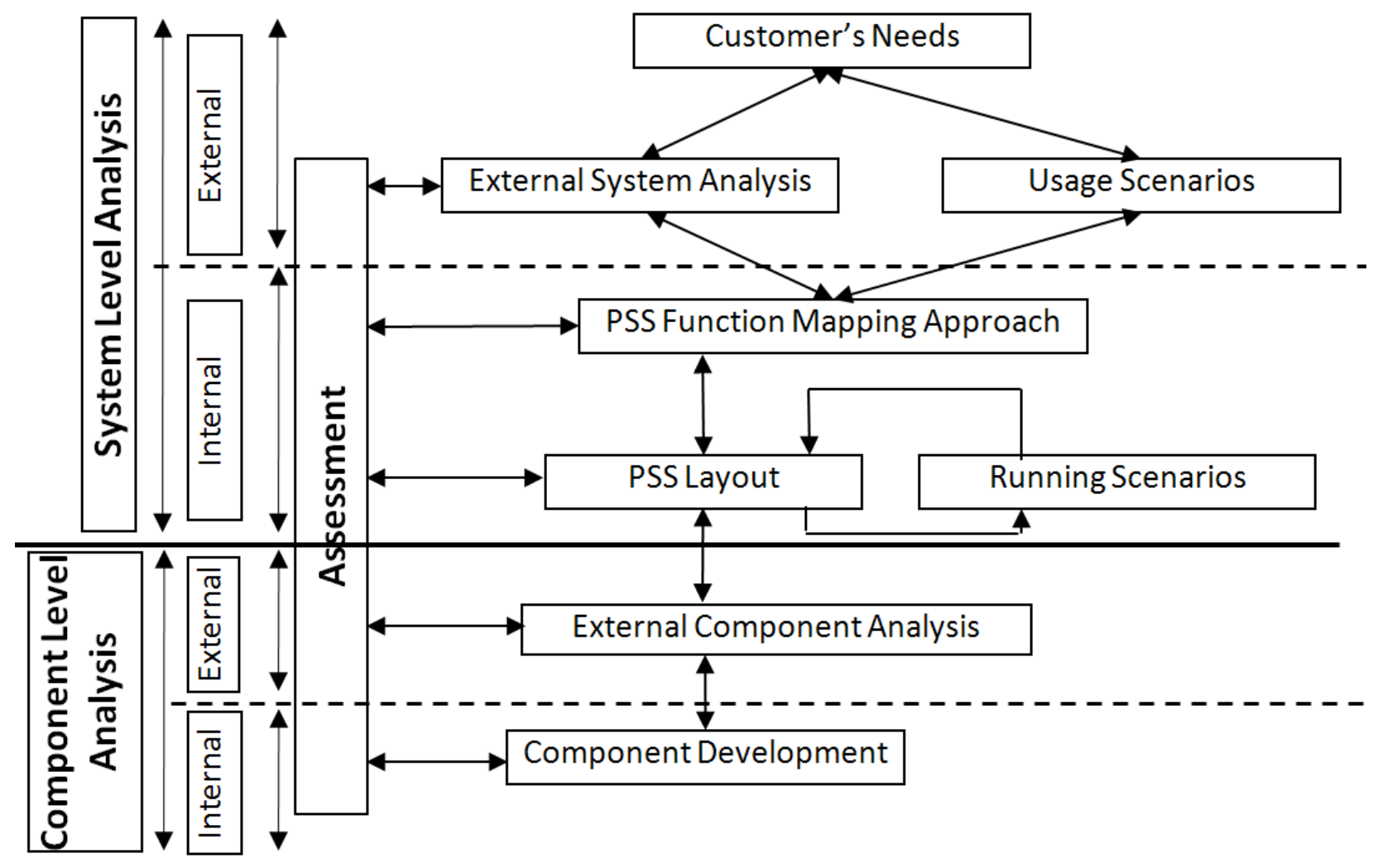

Figure 6 PSS Design (Maussang et al. 2009)

Maussang et al. (2009) insisted on using scenarios during the design process in order to present and situate solutions, to illustrate alternatives and to identify their potentials. They pointed out that scenarios can be appreciated differently by different people because they are highly context dependent.

Alonso-Rasgado et al. (2004) considered the two main aspects of Total Care Products: architecture and business. The architecture consists of the hardware and service support system. Business aspects include markets, risks, partnerships, business chains, agreements, sales and distribution. They described the different combinations of hardware and services available in Total Care products: novel (new) hardware, adapted (from existing) hardware, new service support systems, and adapted service support systems. They mentioned that the challenge is answering how to choose the most suitable combination of products and services to provide the best solution for all parties involved. From literature they showed that the service design process is broadly similar to its equivalent in the hardware field. They proposed the fasttrack design process which breaks down the iterative process between the customer and supplier into a 
number of distinct stages necessary for the creation of the Total Care Product (Figure 7). This will lead to the integration of customer needs and the development of the functional product concept simultaneously. They argued that to carry out the fast-track design process in an efficient manner, a computational tool would be necessary. They empathized that the computational tool should integrate service design, simulation of services, hardware architecture, hardware and service support system costs. They also emphasized that sensitivity analyses could be carried out to determine critical system elements, and cost/benefit analyses carried out to determine resource levels.

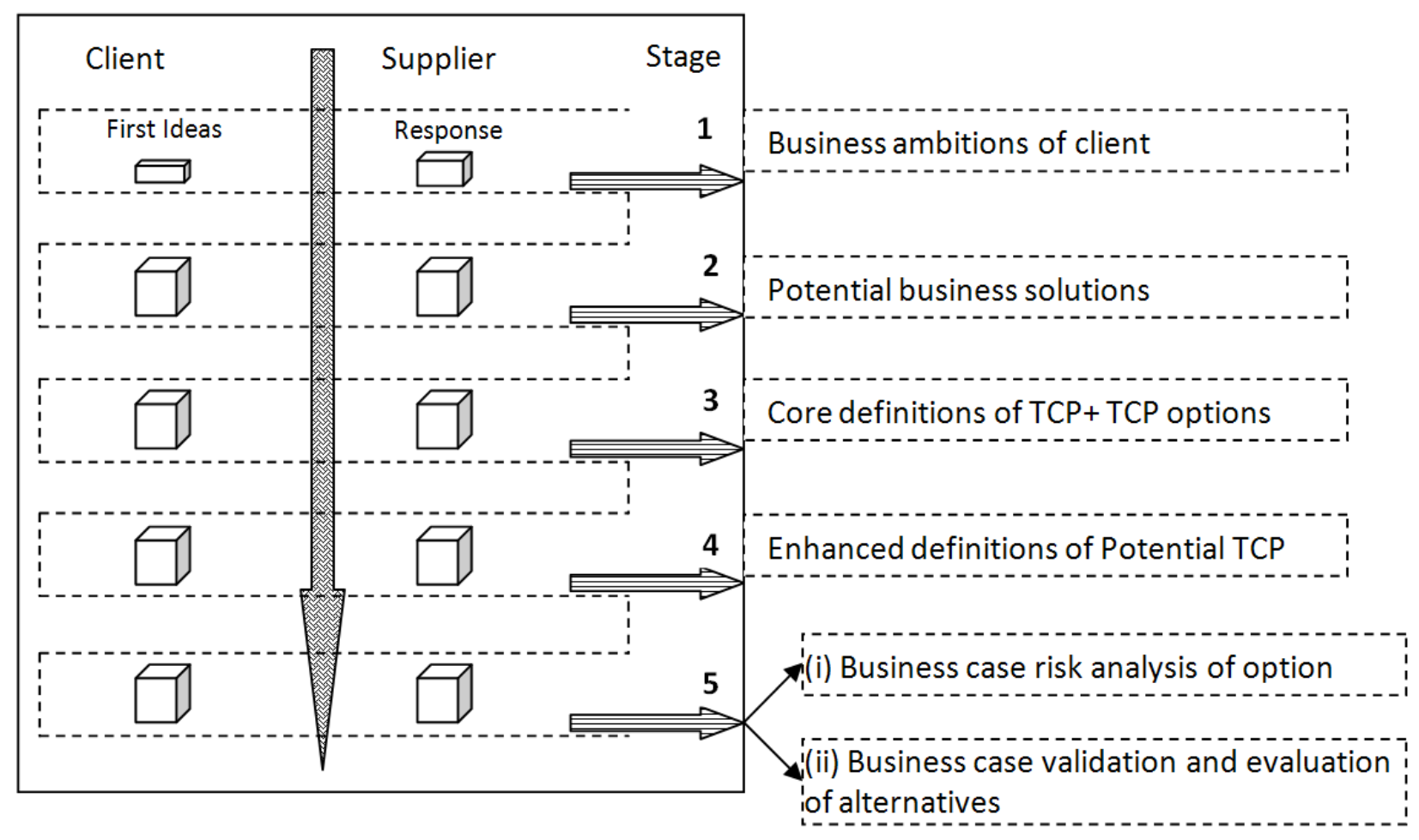

Figure 7 Fast-track design process stages (Alonso-Rasgado et al. 2004)

Alonso-Rasgado et al. (2004) argued that the fast-track design process aids both customer and supplier, reducing the complexity of the process by simplifying decision-making and facilitating the rapid exploration of solutions and alternatives. Importantly, they stressed that use of this methodology ensures that the customer becomes fully aware of the value of the Total Care Product business solution. They claimed that by adopting the methodology supported by the computational tool, it is possible to create a Total Care Product, including the business proposal, in a short period of time. They also said the reliability and maintainability of the service support and total care system are important aspects that require detailed investigation and further research in the future.

Morelli (2002) adapted logical design sequences proposed by Ulrich and Eppinger (2000) for the design of services. Figure 8 represents the design process followed for the development of a support service. It emphasizes two dimensions of space: a problem space and a design space. They claimed that problem phases lead to new solutions, which in turn re-focus the problems and prompt new requirements. 


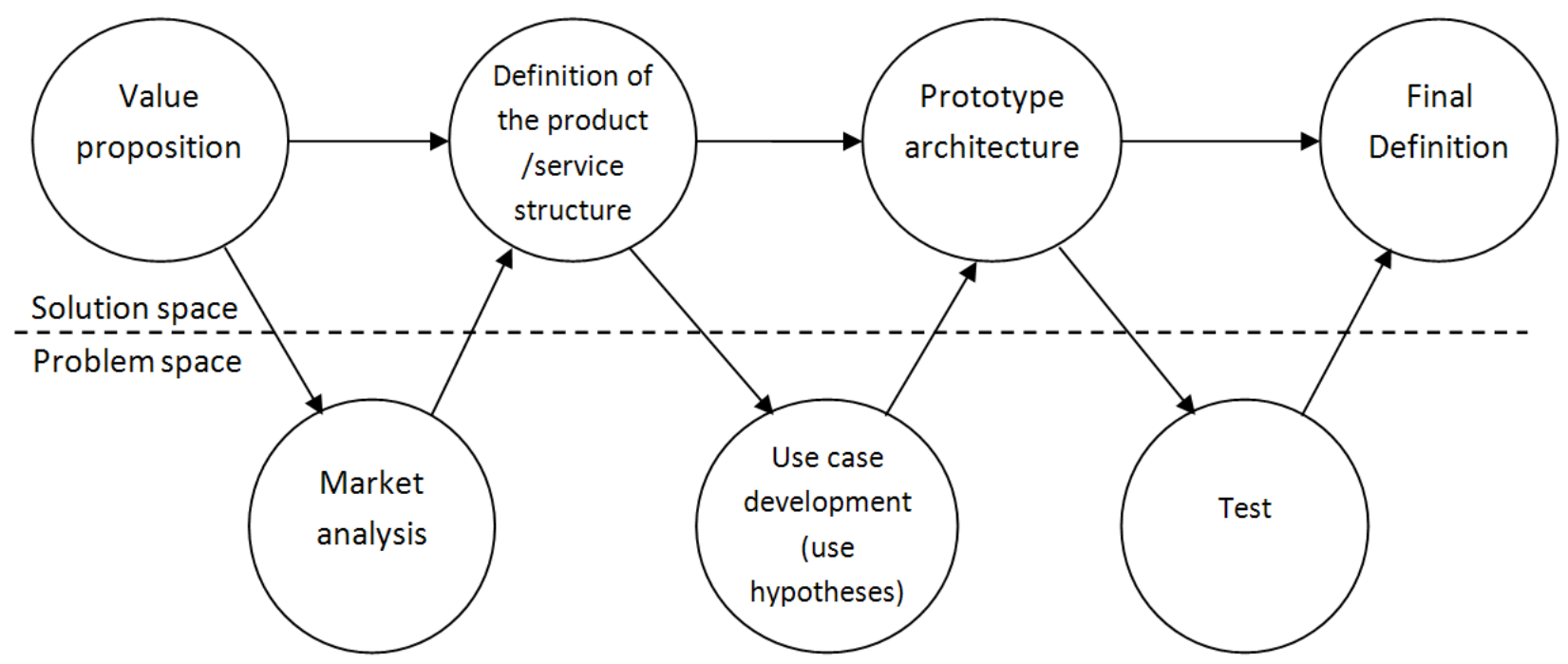

Figure 8 The design process for the development of services (Morelli, 2002)

Tan et al. (2009) proposed four dimensions of PSS that had to be considered: value proposition, product life cycle, activity modelling cycle and the actor network. Figure 9 represents these dimensions together with methodology steps. They argued that these elements cover the essential design elements of a PSS. They noted that an analysis in these four dimensions appears to give a good understanding of how current products and systems work and is also helpful to uncover parts were dimensions could be aligned better. They suggested that a change in one dimension influences the others and the designer has to ensure that each of the dimensions of a new PSS concept support each other in order to be consistent. They noted that PSS design methodology in the context of a company has to deal with management, organisation, coordination and integration of development activities which are not covered in the four dimensions. They mentioned that PSS solutions in the context of a company are dependent on the business strategy, core competencies, structures and/or relationships and are likely to induce change to existing business models. 


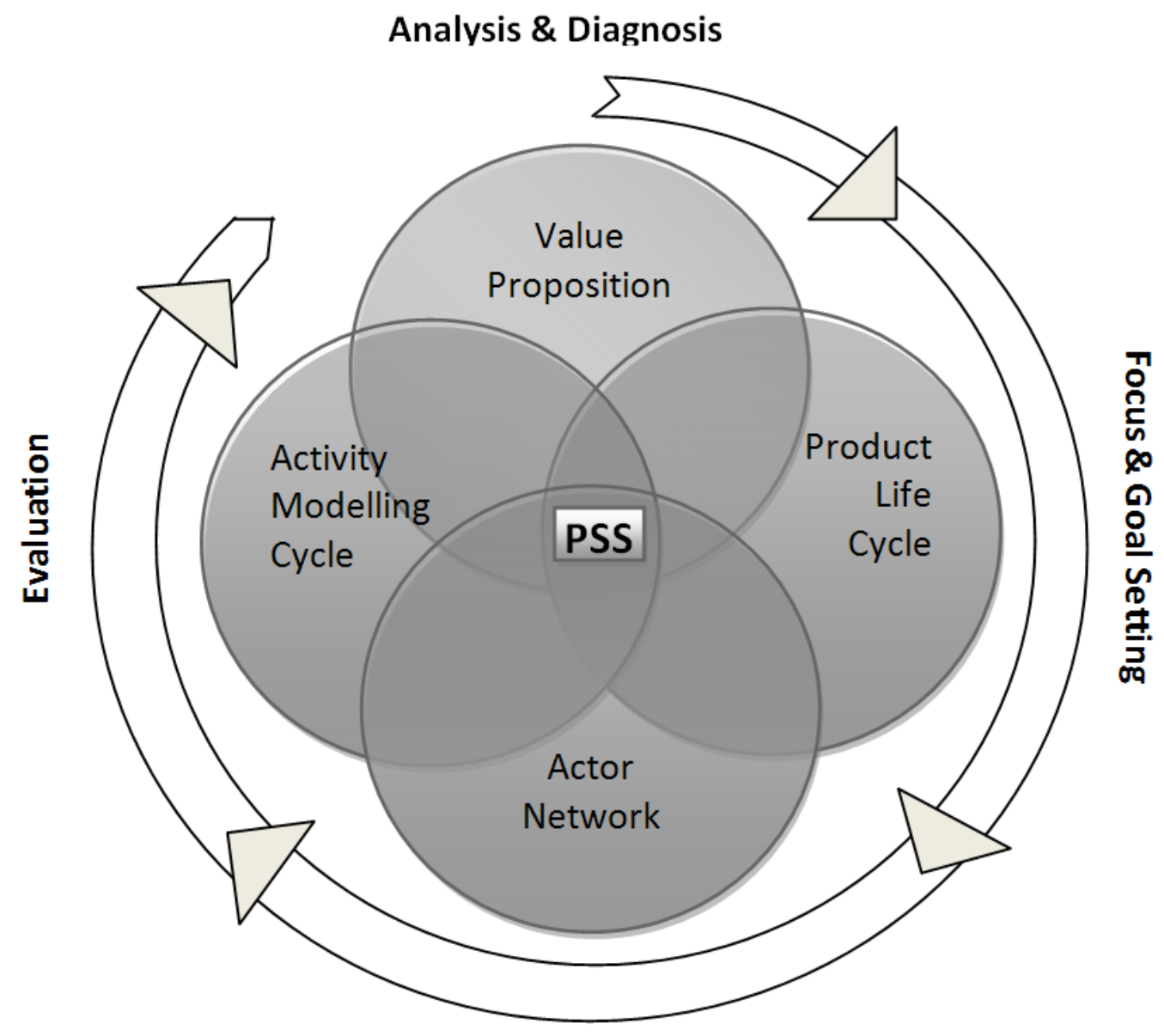

Conceptualization

Figure 9 The four PSS dimensions and design process (Tan et al. 2009)

\subsection{The maturity model}

From the analysis of the methodologies proposed in literature, a maturity model has been generated. Figure 10 illustrates the maturity for different issues considered in the PSS domain. The maturity levels are related to these issues but these are not absolute ratings; that is, the maximum value does not represent the complete development for that issue. The procedure for calculating maturity levels is detailed in Section 3.1. The major conclusions for each of the dimensions considered are (starting from 'Requirements list for developing PSS' in Figure 10, rotating clockwise):

1. The requirements for developing PSS vary between methodologies and detailed requirement lists are not presented. This means that the driving factors (added value, innovation, risks, uncertainties and cost reduction) of PSS are not properly modelled. Ideally, the methodology should also incorporate changing customer requirements. This is an important issue concerning the transfer of risk and uncertainty between stakeholders and should be developed.

2. The roles and responsibilities of the stakeholders co-designing PSS offerings are not clearly defined in the methodologies. In particular, the capabilities of the stakeholders are not discussed. Only the network formulation of stakeholders is mentioned. 
3. The importance of co-creation between stakeholders is only mentioned. It is not detailed enough to understand the uniqueness of this process and how to implement it in real-time. It should enhance flexible network creation.

4. Integrating products and services is discussed as a major objective to be achieved. The overall processes involved in this integration are well detailed. But the intricate steps within each stage are not mentioned.

5. The design processes for creating innovative business models are not often elaborated in methodologies.

6. The influences of business models on product and service offers are not studied.

7. The necessity to incorporate multi-disciplinary approaches within the design methodologies is only mentioned. Since PSS design is inter-disciplinary, many multi-disciplinary approaches should to be incorporated in the design process to create viable and sustainable PSS.

8. The differences in PSS design processes for different types of PSS (Product / Use / Result oriented) are not discussed.

9. The focus on sustainable PSS is only mentioned in all of the analysed methodologies with no support to achieve it. Significant support has to be created to help generate sustainable PSSs.

10. The generation of PSS offerings is considered in most of the methodologies.

11. The evaluation of PSS offerings is at an initial stage of research and should be conducted with long term perspectives necessary to treat related risks and uncertainties.

12. The initial lifecycle phases of PSSs involving planning and design are illustrated in all the methodologies.

13. The other life cycle phases such as implementation and monitoring are not considered sufficiently in the proposed methodologies.

14. The feedback loops between the steps involved in the PSS process and the stakeholders are, most often, vaguely defined.

15. Many techniques are used to detail the representation of PSSs. The merging unique features of these representations into a commonly agreed PSS representation is required.

16. The levels of granularity in PSS representation are not detailed. Parameter identification looks only at the surface level of the PSS. More sub-layer details are required during the conceptual stage to evaluate the solutions in detail.

17. There is a huge variation in the usage of elements between methodologies to create PSSs. Even though each term is defined in literature, a better ontology is required to understand similarities and differences between these elements and within a specified context.

18. The quantitative factors (such as the frequency of services and product operating times) are more correctly represented compared to qualitative factors (for example, customer's experiences and desires, interactions and feedback processes) involved in defining PSS.

19. Significantly, dynamics involved in PSSs characteristics both for requirements and solutions are not adequately considered. A modular approach is highlighted for considering the involved dynamics.

20. The differences between industrial domains (B2B, B2C and B2G) and the maturity of corresponding products are not distinguished in the proposed methodologies. 


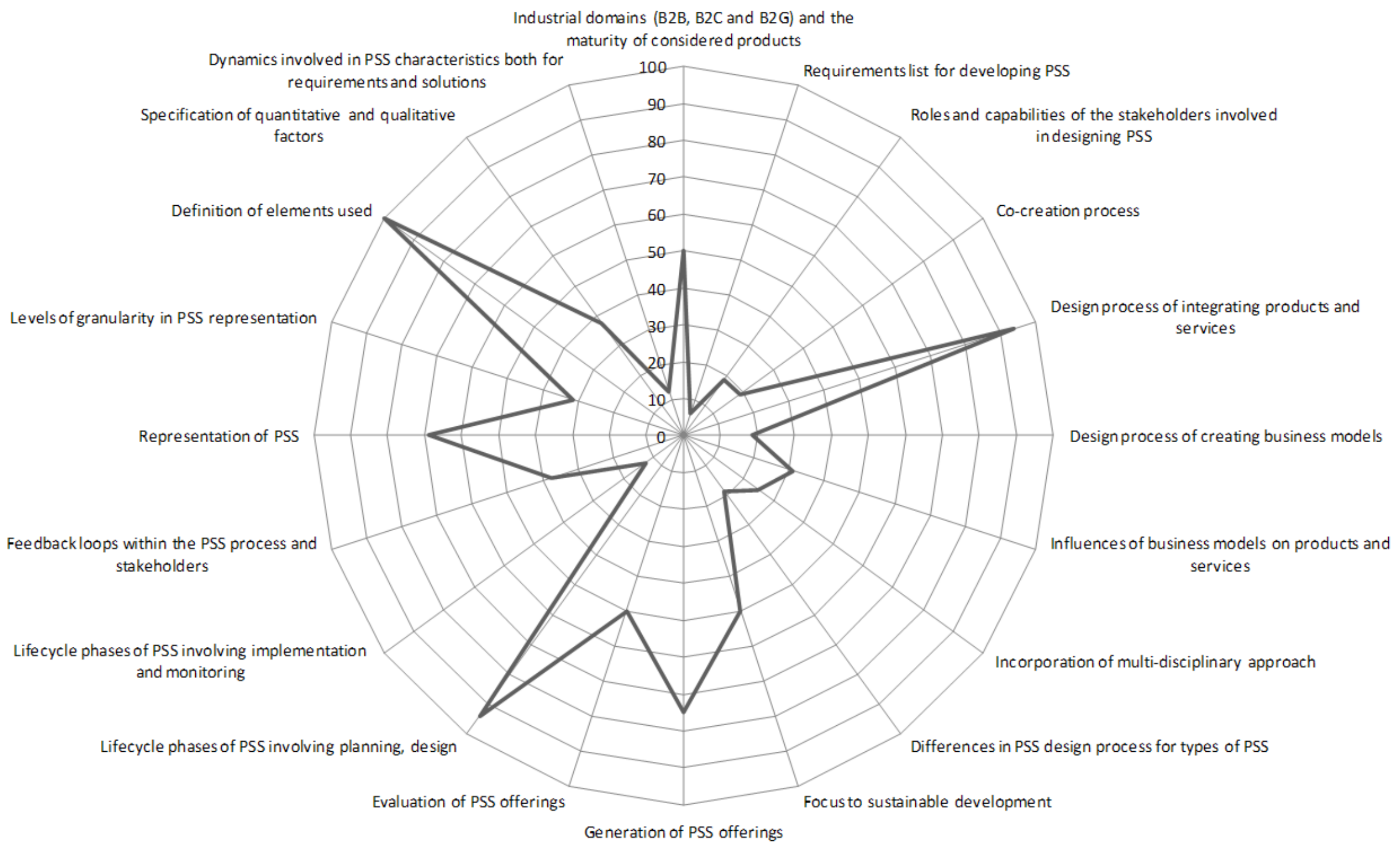

Figure 10 Relative maturity of various issues considered in PSS domain 
To summarize the results of the maturity chart we review the different categories chosen in section 2.4. It is clear that the definition of the context needs to be strengthened and the positioning of stakeholders has to be improved with more precise specifications of requirements and considerations for co-design and cocreation of value. Only the integration of products and services is largely addressed in the design stages, whilst business models and multidisciplinary approaches are overlooked. Sustainability issues are hardly supported. As for life cycle thinking, only the initial phases of design are covered and the other phases and particularly feedback loops have been left out. Representation is unequally treated and essentially there is a need for harmonisation. These findings highlight that substantial improvements and a broadening of scope are required in development of PSS design methodologies. Globally, all of the points need to be substantially detailed to help develop innovative, useful and understandable concepts. In order to improve design methodologies and increase applicability within the industrial context, knowledge transfer between academic researchers and industrial practitioners is of paramount importance. In an industrial context, rigorous definition and representation of technologies are an important issue. In the light of these comments, the next section will consider more deeply two major dimensions as they are viewed in literature: ontology and modelling techniques. In addition, considering the notable absence of models to support and generate sustainable PSS, the dimension of sustainability will be further detailed. Brundtland (1987) laid the basics for Sustainable Development to meet "the needs of the present without compromising the ability of future generations to meet their own needs." Campbell (1996) clarified that the three priorities (economical, social and environmental) resulted in three conflicts: "Grow' the economy, distribute the growth fairly, and in the process not degrade the ecosystem." Recent efforts had been put into business models such as PSS, adapted to a sustainable society (Tan et al, 2010). Indeed, the earliest definition of PSS had said that "a product service-system is a system of products, services, networks of players and supporting infrastructure that continuously strives to be competitive, satisfy customer needs and have a lower environmental impact than traditional business models" (Goedkoop et al. 1999) while Tukker and Tischner (2006) noted that PSS held a prominent part of the sustainability agenda.

\section{Challenges for the development of sustainable PSS}

The three important dimensions identified above are discussed in this section together with the challenges involved in the development process.

\subsection{Ontology for PSS}

Ontology is commonly defined as an explicit formal specification of the terms in the domain and the relations amongst them (Gruber, 1993). Common understanding of terms within the domain could be an important measure to define formal specification. It is clear from the various methodologies reviewed that the terminologies used to describe them vary considerably. Since research leading to develop ProductService Systems is only at an initial stage, it would be good to develop a robust ontology to help on the weak spots. The advantages of developing ontology in initial stages of PSS research are that the effort required is less while there is opportunity for progressive updating as domain understanding evolves and that it encourages methodologies to converge to the commonly shared structure proposed by the ontology. In addition it could help researchers to communicate and share their views without ambiguity and lead to more effective implementation of methods and tools in industry. 
To complete the ontology it is necessary to include important terminologies proposed in the PSS domain from other sources. Business models are widely discussed in the PSS sector. Tucker and Tischner (2005) proposed three models: function-, availability-, and result-oriented use models based on the customersupplier relations. Meier and Massberg (2004) differentiated between business models by: production responsibilities, supply of operating personnel, service initiative, ownership, supply of maintenance personnel and service turn model. Risks and uncertainties are also important parameters and are often sited (Erkoyuncu et al., 2009). Datta and Roy (2009) classified the key cost elements into recurring cost, non-recurring cost, overheads and hidden costs.

Other than business issues, the elements used in PSS design must be reviewed. Factors distinguishing services from products such as intangibility, inseparability, heterogeneity, perishability, simultaneous production and consumption and ownership were discussed by Maussang et al. (2009). They also noted that the development of PSS is influenced by factors such as partners, organization, benefits for the IPS ${ }^{2}$ provider, benefits for the IPS ${ }^{2}$ customer, environment, social considerations, incitement to use IPS ${ }^{2}$, interactions between the system and users and system life-cycle phases. It was commonly noted that the business models, technical artifacts, service activities, the IPS ${ }^{2}$ lifecycle, system context and resources to deliver added value need to be integrated. Mahnel (2007) stressed the quality of the service as an essential factor for customer retention. Brunner and Wagner (2008) identified the following quality criteria for services: presentation and ambiance, reliability, accuracy, correctness, competence, politeness, friendliness, cooperativeness, understanding, authenticity, security, accessibility and availability and ability to communicate and socialize.

Baxter et al. (2008) showed an upper level PSS structure capable of describing a combined product and business- system. The central class 'life cycle system' is comprised of three classes: product, process and resource. Kim et al. (2009) proposed graphical and ontological representations of PSS, including values, product and service elements, and their relations. Shen and Wang (2007) defined product service ontology as the conceptualization of the product service. They said that service involves activity, outcome, process and resources. Jagtap (2008) found that the in-service information required by designers mainly consists of deterioration information, i.e. deterioration mechanisms, deterioration effects, deterioration causes, etc. Also factors such as component failure, operating conditions, maintenance, life cycle cost and reliability were stressed. To sum up, PSS ontology will identify characteristics of requirements, product-services, stakeholders, design processes, life cycle stages, outcomes, business models and support systems. These characteristics have already been explored elsewhere, in other standards such as ISO-10303: Standard for Exchange of Product Model Data (STEP): AP239 (Product Life Cycle Support), AP233 (Systems Engineering Data Representation) (ISO 10303, 2006), and PAS 1094 (Integration of Product and Services) (DIN, 2010). Any standardization effort within the Product Service Systems area would benefit from carefully reviewing already existing, related, standards.

Development of PSS ontology is just starting. The ultimate aim is to develop a common ontology for the PSS community. The challenges involved in its' development can be summarized below.

- Undoubtedly, terminologies proposed within the domain of PSS will increase exponentially in the forthcoming years. Ontology needs to be understood and appreciated, but it should be properly grounded with an appropriate structure to avoid cross-pollination of terminologies. 
- The challenge is not in building various information technologies but to develop a common representation within the PSS community.

- Semantics for each term should be defined properly to avoid ambiguity between stakeholders (researchers and industries).

- Substantial initial effort is required within the PSS community to develop and understand this fundamental structure of PSS.

- A common software platform and mechanism needs to be developed to update the ontology progressively.

- A PSS ontology should be intuitive so that it could be easily and appropriately implemented in industries.

- Exclusiveness and exhaustiveness of the PSS ontology will evolve over time.

- Many applications need to be generated around the ontology to validate and prove its usefulness.

\subsection{System modelling techniques in PSS Design}

The primary motivation in PSS modelling is to co-create conceptual models that can be systematically shared by stakeholders. This requires a multi-disciplinary system's approach to create viable offerings. A large variety of representation techniques have been used and discussed in literature.

Representation techniques have been used in PSS design methodologies to define different processes involving products and services. They include UML, SADT, Functional Analysis, extended Blueprint, BPMN and SysML. Morelli (2006) argued that an Integrated DEFinition method of modelling functionality and information modelling (IDEF0) is adequate in systems with a higher grade of predictability, but cannot cover an infinite number of configurations and situations due to subjectivity and unpredictability. Morelli (2002) detailed the provision of UML representation for use cases used to list requirements for each functional element of a system. Durugbo et al. (2010) argued that Data Flow Diagrams (DFD) may be suitable for modelling the organisation of a PSS, while the IDEF or Graphes à Résultats et Activités Interreliés (GRAI) approaches may be suitable for representing PSS manufacturing processes. They noted that a small company may adopt a flexible and easy to maintain model such as a DFD, whilst a large company requiring a complete mapping of its functions and processes may opt for a Design structure matrix (DSM). Service Blueprinting proposed by Shostack (1982) provides good insight into customer interaction by representing the line of visibility and the line of interaction. Becker et al. (2010) found that interfaces between products and services and the degree of integration are seldom addressed in modelling languages. They highlighted a meta-model to integrate various approaches into an adequate PSS representation. Knutilla et al. (1998) analysed various process specification languages through requirements grouped into the following categories: resource representation and characteristics; task/process representation and basic characteristics; resource characteristics; precedence/sequences; and date/time. They observed that often these requirements were addressed through a combination of approaches. The requirement list needs to be extended for PSS modelling.

Visual modelling languages have been used for supporting functional and behaviour analysis. Long (2002) explored languages like standard Functional Flow Block Diagrams (FFBD), N2 charts, and Behaviour Diagrams. He proposed that states and models furnish the base to represent operate systems, predict future states, control the desired states, and assess performance. Ingham (2006) showed that State Analysis could be synthesized with a functional analysis model-driven process as a more comprehensive and rigorous 
approach to system behaviour modelling. Browning (2001) noted that representation of function forms that are sequential, concurrent, coupled or conditional is possible in the Design Structure Matrix (DSM). Kordon et al. (2005) argued that the iterative decomposition process is part of traditional functional analysis and decomposition results in a hierarchy of functions, physical components and requirements and the links between them. Becker et al. (2008) argued that functional decomposition modelling could help identify products and services within a PSS.

Information is an aspect in PSS representation. Information Flow Diagram models for PSS were reviewed by Durugbo et al. (2010). PSS was considered in terms of open systems, social constructs and business models. They argued that modelling a PSS based on function orientation offers a useful way to distinguish system inputs and outputs with regards to how data is consumed and information is used. They insisted that modelling the information flow for a PSS is an important indicator to appreciate the level of redundancy and inefficiency in the PSS delivery process involving actors, roles and scenarios. Balmelli (2007) noted that SysML provides features which support traceability, rationalization of design, inter-team communication, decision tools, change impact analysis and manage dependencies between processes and the produced artefacts. To help collaboration between domain practitioners, system architects, developers and testers, the Model-Driven Architecture ${ }^{\circledR}(\mathrm{MDA} \circledast)$ ) framework specifies three viewpoints of a system: computation independent-, platform independent-, and platform specific- (OMG, 2003). Dori (2002) proposed Object-Process Diagrams (OPD) with constrained natural language sentences known as ObjectProcess Languages (OPL) to express the function, structure, and behaviour of systems in an integrated, single model.

The characteristics expected from the applied modelling techniques are:

- They must be clear, flexible, unambiguous and consistent, simple, complete, extensible, intuitive, easy to learn, capable of translating and illustrating areas of interest with varying levels of detail and capable of rationalizing capture (aid to understand decisions).

- They should be widely used and supported in industry with less but more consistent notations supported by standards. Also, they need to be traceable, easy to interpret and not time-consuming.

- They must represent dependencies and highlight the impact of changes made, be easy to integrate with related methodologies and capable of creating different views supporting visibility and interactions that are easy to document and easy to maintain.

The important issues that will help the process of co-creation of PSS can be detailed as follows:

- The specificities of PSS call for multi-disciplinary, multi-level approaches. The PSS designer, integrating diverse fields that can be technical, managerial or service, needs to constantly move from a global vision of the system down to detailed features describing the interactions between the physical and service elements that compose it. To achieve this, two different strategies are possible: the first seeks a unified model capable of piloting the overall system and is inspired by system engineering methods or models such as the V-cycle. The advantage would be their capacity to model complex multi-technological systems with the difficulty of integrating the great variety of views necessary; the second will aggregate heterogeneous models or views of the different sub-parts of the system in a clear coherent framework. This approach would model individual components precisely, although the sum of the components is not equivalent to the total. 
- Detailed research studies are required to help stakeholders choose the appropriate modelling techniques based on applications at different stages of PSS modelling.

- PSS models must represent stakeholders, products, services, support systems, business elements and processes, work flow and interactions amongst them. Most importantly the models should represent value (economic, environmental and social) created by the offering and its' associated risks. Other important elements that should be modelled are the functional maps and behavioural (state changes and control) (un)predictability of the system. Along with these elements, the capabilities of the stakeholders should be more adequately represented.

- Usually, constructing models is very time-consuming. Reusing models wherever possible is the best practice and has been emphasised in PSS tools such as Service CAD and Service Explorer. However, these tools do not provide any constructed domain models to use or further develop in the particular applications. It means that primary domain knowledge involved in designing PSS needs to be captured and structured for further development.

- Even though many representations support evaluation processes, they need to be detailed with reference to PSS characteristics. They should facilitate validation of system behaviour in a given context; verify suitability of the system and analyse performance (the ability to meet requirements with respect to inputs). Simulating and analysing what-if scenarios would be advantageous in predicting system dynamics. Furthermore, optimizing the development system would be the final and iterative step for system improvement.

\subsection{Sustainability}

For the eight methodologies there is a clear link between the PSS notion, dematerialization and sustainability and their works trace the major ideas making PSS fundamentally sustainable. Indeed they saw integrated products and services as a strategy for sustainable competitive product development (Kimita et al., 2009, Tan et al., 2009, Meier et al., 2010). Aurich et al. (2006) stressed the potential of technical services for more sustainable production and consumption. For Tomiyama (2001), dematerialization of products require enriching service contents while Maussang et al. (2009) stressed the necessity to take into account the environmental, economical and social aspects of PSS regarding sustainable development issues. Finally, Morelli (2006) considered PSS as fundamental for the development of solution oriented partnerships, and consequently for sustainable solutions.

However, some differences can be seen at the point of entry they had chosen. Tomiyama (2001) stipulated that the Post Mass Production Paradigm aims at qualitative satisfaction rather than quantitative sufficiency. Maussang et al. (2009) saw that to resolve environmental problems, developed countries must decouple economic growth and environmental pressure. One solution is to move from product to servicebased economies. For Kimita et al. (2009), PSS affords opportunities for manufacturers to differentiate their products by meeting diversely segmented customer needs in a sustainable manner. Tan et al. (2009) stated that PSS approaches are sustainable innovation strategies in a total life cycle perspective and Meier et al. (2004) inscribed IPS ${ }^{2}$ in the search for technological and economical potential that increase the competitiveness and harmonize the ecology and economy in one target system. Aurich et al. (2006) developed the potential of technical services for more sustainable production and consumption, while Alonso-Rasgado et al. (2004) stressed the importance of re-use and remanufacturing of hardware for sustainable design. Morelli (2002) emphasised the social aspect of PSS during the use phase. 
The three basic principles of sustainable development: economic; social and environmental, are treated to different extents. Economic sustainability covers the shift from the consumption of energy and materials to service artefacts for Tomiyama (2001) leading to changes in the economic model (Maussang et al., 2009) and the entire production and consumption system (Tan et al., 2009). Product ownership is reconsidered to focus on more effective use rather than added-value generation (Tomiyama, 2001). Social considerations include social value and recognition (Maussang et al., 2009) while PSS have the potential to improve access to technology worldwide (Meier et al., 2010) in a more geographically balanced work distribution (Stahel, 1994). Environmental aspects reflecting regulations and companies' sustainable development objectives must be included early in the design process (Maussang et al., 2009). The intensive use of capital goods through renting, sharing and pooling could lead to high environmental gains in principle as a result of reduced consumption of resources and waste generation (Meier et al., 2010), whereas the replacement of components should be designed to be carried out under factory-controlled remanufacturing conditions (Alonso-Rasgado et al., 2004). Other key factors influencing sustainability are life cycle considerations; value co-production processes; knowledge management and actor networks. Moreover, the value of products throughout their life cycle has to be balanced against cost (Hara et al., 2009, Tan et al., 2009).

Recommended models and tools cover more general environmental tools such as Life-Cycle Analysis, Design-for-X, whilst some specific PSS and service tools cover environmental aspects. Simultaneous Engineering can be used for manufacturing, remanufacturing and recycling and the Integrated Process Model provides a full life cycle oriented process module library (Aurich et al., 2006). The functional block diagram (Maussang et al., 2009) and the flow model (Shimomura et al., 2008) introduce environmental and social aspects into the evaluation of PSS. The flow model establishes priorities in sustainability issues. The Product Life Gallery visualises mapping of stakeholder needs and activities, life-cycle, environmental effects and other trade-offs (Tan et al., 2009). Morelli (2006) has argued that the discussion about methodology to design PSS is still open and critical for the development of sustainable solutions, whilst Bartolomeo et al., (2003) have stated that few studies have demonstrated the environmental effectiveness of services.

The challenges for the development of sustainable PSS are:

- PSS must integrate economic, environmental and social considerations in a holistic approach in order to produce radical changes and identify the degrees of freedom for change in the overall production and consumption system.

- Environmentally conscious design and manufacturing in closed-loop economies must strongly consider customers' behaviour in the use phase.

- PSS must afford opportunities for manufacturers to develop the business potential of environmentally conscious design and differentiate their products by meeting diversely segmented customer needs in a sustainable manner.

- Methodological tools for designers must be developed to analyse PSS as social constructs and extend value and functional units to include the prolificacy of social and cultural significances of products and services such as history, status, prestige, identity and so forth.

- PSS must consider product design within the product life-cycle perspective and combine the design phases and activities with corresponding organizational issues to provide product engineers with efficient means for optimization in the life cycle perspective. 
- They must provide more convenience through service so as to intensify physical use with less energy and material consumption.

- It is necessary to identify the main stakeholders in the business relationships and develop close collaboration between the customer and supplier in an iterative procedure involving needs, expectations and solution-exploration that ultimately would lead to the creation of the functional product.

- The cost of the PSS (including monetary cost as well as physical load, mental load, and environmental burdens) must be compared to the value provided.

- Sustainability, availability and higher customer satisfaction must be guaranteed over the life cycle due to intensified service and knowledge content and data sharing throughout the product life cycles.

\section{Conclusions}

The paper has reviewed the state-of-the-art in PSS design methodology and research gaps were identified and discussed. In particular, eight of the most referred to methodologies in scientific literature were studied in order to evaluate the current level of maturity. Firstly, the different points of view regarding services and PSS along with their major issues were highlighted and discussed. Next, the tools and methods proposed and the elements used in the tools together with current research challenges were studied in detail for each research group. A maturity model was then used to illustrate the progress in function of different dimensions. The last section discussed the challenges for the development of sustainable PSS. Three dimensions were underlined: ontology; modelling techniques and sustainability.

Analysis of service and PSS definitions and challenges mentioned in literature identified twenty dimensions grouped into six categories to be addressed in order to develop effective PSSs. The categories covered were context, stakeholders, design stages, development cycle, life cycle and representation. Eight state of the art methodologies in the literature were then selected to be deeply analysed in-depth using this table, thus providing a maturity model of state of the art PSS design. The referred papers were assessed qualitatively using a three point scale (discussed, mentioned and not at all considered) for each dimension.

The maturity model highlights that current PSS design methodologies essentially focus on three dimensions: design processes for integrating products and services, definitions of new terminologies and considerations of planning and design lifecycle phases. Other dimensions need adequate attention for significant improvement. They include development of detailed requirement lists, better understanding of issues concerning implementation and monitoring of PSS, definition of the roles and capabilities of the stakeholders involved, design processes for creating innovative business models and better understanding of how the different types of PSS affect the design process. Finally, although it has been commonly agreed that designing PSS is a co-creation process, this point should be more appropriately addressed.

It has been noted that the methodologies had not been evaluated in real time industrial contexts. Evaluation in industry could provide more detail concerning the weaker dimensions and help to identify the PSS design needs from industry. Collaboration between academic researchers and industrial practitioners is vital to ensure and encourage the applicability of the proposed methodologies in industry. To foster this process, issues involving the use of terminologies and the representation of PSS modelling have been highlighted and discussed. Discussion will force the PSS community to develop a unique PSS ontology helping to understand the fundamental structures of PSS, facilitating the transfer of knowledge 
and updating through progressive recognition. PSS modelling must be considered through multidisciplinary and multi-level approaches. The analysis highlights the importance of representing and validating stakeholder capabilities and value during the development of PSS offerings. Support to drive sustainability and the benefits derived from the application of PSS concepts are not detailed in the proposed methodologies. Sustainability must include the three pillars of economics, social and environment within a life cycle perspective. Environmental considerations should be crossed with value creation and the use-phase of the PSS.

On the whole, the review shows that the field of PSS design is as yet at an initial stage of development. Furthermore, the gaps identified within current literature stress the great amount of research still required to develop an efficient PSS design methodology.

\section{Acknowledgements}

This research was funded by the Cranfield Innovative Manufacturing Research Centre (EPSRC Grant EP/E001874/1) as part of the research project "Capability based conceptual PSS design".

\section{References}

Albrecht, K. and Zemke, R., 1985. Service America! : Doing business in the new economy. Homewood, Ill., Dow Jones-Irwin.

Alonso-Rasgado, T. ,Thompson, G. and Elfström, B., 2004. The design of functional (total care) products, Journal of Engineering Design, 15 (6), 515-540.

Alonso-Rasgado, T., and Thompson, G., 2006. A rapid design process for Total Care Product creation, Journal of Engineering Design, 17 (6), 509-531.

Aurich, J., Fuchs, C. and Wagenknecht, C., 2006a. Life cycle oriented design of technical Product-Service Systems, Journal of Cleaner Production, 14 (17), 1480-1494.

Aurich, J.C., Fuchs, C., and Wagenknecht, C., 2006b. Modular design of technical product-service systems, Brissaud, D., et al. (eds.), Innovation in Life Cycle Engineering and Sustainable Development, Springer, 303-320.

Baines, T. et al. 2007. The state-of-the-art in Product Service Systems. Journal of Engineering Manufacture, IMechE, Part B: J. Engineering Manufacture, 221, 1543-1552.

Balmelli, L., 2007. An Overview of the Systems Modeling Language for Products and Systems Development, Journal of Object Technology, 6 (6), 149-177.

Baxter, D., Doultsinou, N., Roy, R. and Gao, J., 2008. A life cycle model for product-service systems design, In: 5th International Conference on Digital Engineering Technology (DET 2008), Nantes, France.

Becker, J., Beverungen, D.F. and Knackstedt. R., 2010. The challenge of conceptual modeling for product- service systems: status-quo and perspectives for reference models and modeling languages, Inf Syst E-Bus Manage, 8, 33-66. 
Browning T.R., 2001. Applying the design structure matrix to system decomposition and integration problems: a review and new directions. IEEE Trans Eng Manage, 48, 292-306.

Brundtland, G.H., 1987. Our Common Future, Report of the World Commission on Environment and Development, World Commission on Environment and Development.

Brunner, F.J., and Wagner, K.W., 2008. Taschenbuch Qualitätsmanagement, Carl Hanser Verlag München, Wien.

Bullinger, H., Ahnrich, K. F., Meiren, T., 2003. Service engineering-methodical development of new service products Int. J. Production Economics, 85, 275-287.

Campbell, S., 1996. Green cities, growing cities, just cities? Urban planning and the contradictions of sustainable development, Journal of American Planning Association, 62, 296-312.

Datta, P.P., and Roy, R., 2009. Cost Modelling Techniques for Availability Type Service Support Contracts: a Literature Review and Empirical Study, Proceedings of the $1^{\text {st }}$ CIRP IPS ${ }^{2}$ Conference, Cranfield University, UK, 216-223.

DIN - Deutsches Institut für Normung, e.V., 2010, PAS 1094:2009-12 (D) Hybride Wertschöpfung Integration von Sach- und Dienstleistung Technische Regel Ausgabe: 2009-12, Deutsch Originalsprache, Germany.

Dori, D., 2002. Object-Process Methodology: A Holistic Systems Paradigm, Springer-Verlag: Berlin Heidelberg, Germany.

Durugbo, C., Tiwari, A., and Alcock, J.R., 2010. A review of information flow diagrammatic models for product-service systems, Int J Adv Manuf Technol, 52 (9-12), 1193-1208.

Erkoyuncu, J. A., Roy, R., Shehab, E. and Wardle, P., 2009. Uncertainty challenges in service cost estimation for product-service systems in the aerospace and defence industries, Proceedings of the $1^{\text {st }}$ CIRP IPS² Conference, Cranfield University, UK, 200-207.

Goedkoop, M., van Haler, C., te Riele, H., and Rommers, P. 1999. Product Service-Systems, ecological and economic basics. Report for Dutch Ministries of Environment (VROM) and Economic Affairs (EZ).

Gruber, T.R. 1993. A Translation Approach to Portable Ontology Specification. Knowledge Acquisition, $5,199-220$.

Hara, T., Arai, T., Shimomura, Y. and Sakao, T., 2009. Service CAD system to integrate product and human activity for total value, CIRP Journal of Manufacturing Science and Technology, 1 (4), 262-271.

Ingham, M., 2006. State Analysis Overview: What PSEs ought to know, Briefing Slides (internal document), Jet Propulsion Laboratory, California Institute of Technology, Pasadena, CA.

Kim, Y.S., Wang, E., Lee, S.W. and Cho, Y.C, 2009. A Product-Service System Representation and Its Application in a Concept Design Scenario, Proceedings of the $1^{\text {st }}$ CIRP IPS ${ }^{2}$ Conference, Cranfield University, UK, 32-39. 
Kimita, K., Shimomura, Y. and Arai, T., 2009. A customer value model for sustainable service design. CIRP Journal of Manufacturing Science and Technology, 1 (4), 254-261.

Knutilla, A., Schlenoff, C., Ray, S., Polyak, S.T., Tate, A., Cheah S.C., and Anderson R.C., 1998. Process Specification Language: An Analysis of Existing Representations, NISTIR 6160, National Institute of Standards and Technology, Gaithersburg, MD.

Komoto H., and Tomiyama T., 2008. Integration of a service CAD and a life cycle simulator, CIRP Annals - Manufacturing Technology, 57, 9-12.

Komoto, H., 2009. Computer Aided Product Service Systems Design (Service CAD and its integration with Life Cycle Simulation), PhD Thesis, Delft University of Technology, Delft, the Netherlands.

Komoto, H., and Tomiyama T., 2009. Design of Competitive Maintenance Service for Durable and Capital Goods using Life Cycle Simulation. International Journal of Automation Technology, 3 (1), 63-70.

Kordon, M., Wall, S., Stone, H., Blume, W., Skipper, J., Ingham, M., Neelon, J., Chase, J., Baalke, R., Hanks., D., Salcedo, J., Solish, B., Postma, M. and Machuzak, R., 2007. Model-Based Engineering Design Pilots at JPL, Proc. of IEEE Aerospace Conference '07.

Luczak, H., Gill, C., and Sander, B., 2007. Architecture for Service Engineering - The Design and Development of Industrial Service Work, Advances In Services Innovations, Springer, I, 47-63.

Mahnel, M., 2007. Fit for best Service, Stellhebel für den Service von morgen - lernen von den Servicechampions, Impuls Management Consulting.

Manzini, E., 1993. Il Design dei Servizi,La Progettazione del Prodotto- Servizio, Design Management, 4, $7-12$.

Maussang, N., Zwolinski, P. and Brissaud, D., 2009. Product-service system design methodology: from the PSS architecture design to the products specifications, Journal of Engineering Design, 20 (4), 349 366.

Meier, H., and Massberg, W., 2004. Life Cycle-Based Service Design for Innovative Business Models, CIRP Annals - Manufacturing Technology, 53 (1), 393-396.

Meier, H., Roy, R., and Seliger, G., 2010. Industrial Product-Service Systems - IPS 2 , CIRP Annals Manufacturing Technology, 59 (2), 607-627.

Ministry of Defence, 2005. Defence Industrial Strategy. London: Her Majesty’s Stationery Office.

Mont, O., 2000. Product-Service Systems. Shifting corporate focus from selling products to selling product-services: a new approach to sustainable development. Lund.

Morelli, N., 2002. Designing product/service systems. A methodological exploration, Design issues, 18(3), 3-17.

Morelli, N., 2006. Developing new product service systems (PSS): methodologies and operational tools, Journal of Cleaner Production, 14, 1495-1501. 
Müller, P., Kebir, N., Stark, R., and Blessing, L., 2009. PSS Layer Method - Application to Microenergy Systems, Introduction To Product/Service-System Design, Springer, Part I, 3-30.

Ng, I., and Yip, N., 2009. Identifying Risk and its Impact on Contracting Through a Benefit Based-Model Framework in Business to Business Contracting: Case of the Defence Industry", Proc. of ICMR conference '09.

Rexfelt, O., and Ornäs V. H., 2009. Consumer acceptance of product-service systems Designing for relative advantages and uncertainty reductions, Journal of Manufacturing Technology Management, 20 (5), 674-699.

Sadek, T., and Theiss, R., 2010. Knowledge Based Assistance for Conceptual Development of Industrial Product-Service Systems, Proceedings Of The 6th CIRP-Sponsored International Conference On Digital Enterprise Technology, Advances in Intelligent and Soft Computing, 66, 1647-1664.

Sakao, T. and Shimomura, Y., 2007. Service Engineering: a Novel Engineering Discipline for Producers to Increase Value Combining Service and Product, Journal of Cleaner Production, 15, 590-604.

Sakao, T., Shimomura, Y., Sundin, E. and Comstock, M., 2009. Modeling design objects in CAD system for Service/Product Engineering, Computer-Aided Design, 41, 197-213.

Shen, J. and Wang, L., 2007. A New Perspective and Representation of Service, International Conference on Wireless Communications, Networking and Mobile Computing, WiCom '07.

Shimomura, Y., Hara, T. and Arai, T., 2008. A service evaluation method using mathematical methodologies, CIRP Annals - Manufacturing Technology, 57, 437-440.

Shimomura, Y., Hara, T. and Arai, T., 2009. A unified representation scheme for effective PSS development, CIRP Annals - Manufacturing Technology, 58, 379-382.

STEP Application Handbook, 2006. ISO 10303, VERSION 3, Prepared and Published by SCRA. (www.uspro.org/documents/STEP_application_hdbk_63006_BF.pdf, Accessed online, October, 2011).

Tan, A. R., Matzen, D., McAloone, T., and Evans, S., 2010. Strategies for Designing and Developing Services for Manufacturing Firms, CIRP - Journal of Manufacturing Science and Technology, 3 (2), 9097.

Tan, A., McAloone, T.C. and Hagelskjær, L.E., 2009. Reflections on product/service-system (PSS) conceptualisation in a course setting, International Journal of Design Engineering.

Tomiyama, T., 2001. Service engineering to intensify service contents in product life cycles, Second international symposium on environmentally conscious design and inverse manufacturing, Tokyo, Japan. 613-618.

Tomiyama, T., Shimomura, Y. and Watanabe, K., 2004. A Note on Service Design Methodology. Proc. of DETC ’04, ASME, Paper No. 57393.

Tucker, A., and Tischner, U., 2005. New Business for Old Europe - Product-Service Development, Competiveness and Sustainability, Greanleaf Publishing, Sheffield, UK. 
Tukker, A., and Tischner, U., 2006. Product-services as a research field: past, present and future. Reflections from a decade of research. Journal of Cleaner Production, 14(17), 1552-1556.

Ueda, K., Takenaka, T., and Fujita K., 2008. Toward value co-creation in manufacturing and servicing, CIRP Journal of Manufacturing Science and Technology, 1, 53-58.

Ulrich, K.T., and Eppinger S.D., 2000. Product Design and Development, McGraw-Hill.

van Halen, C., Vezzoli, C., Wimmer R., 2005. Methodology For Product Service System Innovation, How to implement clean, clever and competitive strategies in European industries ISBN: 90-232-4143-6, Royal Van Gorcum, Assen, Netherlands.

Vandermerwe, S., 2000. How increasing value to customer improves business results, MIT Sloan Management Review, 42(1), 27-37.

Weber, C., Steinbach, M., Botta, C., and Deubel, T., 2004. Modelling of Product-Service Systems (PSS) Based on the PDD Approach, International Design Conference - Design 2004, Dubrovnik, May 18 - 21.

Welp, E.G., Meier, H., Sadek, T., and Sadek, K., 2008. Modelling Approach for the Integrated Development of Industrial Product-Service Systems, The 41st CIRP Conference on Manufacturing Systems '08. 
Table 1 Details of methodologies chosen for in-depth analyses

\begin{tabular}{|c|c|c|}
\hline Approach & Description & References \\
\hline Service CAD & $\begin{array}{l}\text { A method to design business models that increase eco- } \\
\text { efficiency from a systemic perspective. }\end{array}$ & $\begin{array}{l}\text { Tomiyama, 2001; Komoto } \\
\text { and Tomiyama, 2008, 2009; } \\
\text { Komoto, 2009; }\end{array}$ \\
\hline $\begin{array}{l}\text { Service Model } \\
\text { Service Explorer }\end{array}$ & $\begin{array}{l}\text { Focuses on service engineering to design products with } \\
\text { a higher added-value from enhanced services. }\end{array}$ & $\begin{array}{l}\text { Sakao and Shimomura, 2007; } \\
\text { Shimomura et al. 2008, 2009; } \\
\text { Sakao et al. 2009; Kimita et } \\
\text { al. 2009; Hara et al. 2009. }\end{array}$ \\
\hline $\begin{array}{l}\text { Integrated product and service } \\
\text { design processes }\end{array}$ & $\begin{array}{l}\text { Exploits the potential of interrelations between } \\
\text { physical products and non-physical services and the } \\
\text { development of corresponding design processes. }\end{array}$ & Aurich et al. 2006a and b. \\
\hline $\begin{array}{l}\text { Fast-track Total Care design } \\
\text { process }\end{array}$ & $\begin{array}{l}\text { Develops innovative offerings consisting of hardware } \\
\text { and services integrated to provide complete functional } \\
\text { performance. }\end{array}$ & $\begin{array}{l}\text { Alonso-Rasgado et al., 2004; } \\
\text { Alonso-Rasgado and } \\
\text { Thompson, } 2006 .\end{array}$ \\
\hline PSS Design & $\begin{array}{l}\text { Assists engineers in the joint development of physical } \\
\text { products and interacting services to generate more } \\
\text { added value. }\end{array}$ & Maussang et al. 2009. \\
\hline $\begin{array}{l}\text { Heterogeneous IPS }{ }^{2} \text { concept } \\
\text { modelling }\end{array}$ & $\begin{array}{l}\text { A model based approach of diffuse borders between } \\
\text { products and services that generates heterogeneous } \\
\text { Industrial Product-Service Systems (IPS }{ }^{2} \text { concept } \\
\text { models in the early phase of IPS }{ }^{2} \text { development. }\end{array}$ & $\begin{array}{l}\text { Meier and Massberg, 2004; } \\
\text { Welp et al. 2008; Sadek and } \\
\text { Theiss, } 2010 .\end{array}$ \\
\hline $\begin{array}{l}\text { The dimensions of PSS } \\
\text { Design }\end{array}$ & $\begin{array}{l}\text { A comprehensive description of PSSs capable of } \\
\text { generating new PSS concepts. }\end{array}$ & Tan et al. 2009, 2010. \\
\hline $\begin{array}{l}\text { The design process for the } \\
\text { development of an integrated } \\
\text { solution }\end{array}$ & $\begin{array}{c}\text { Development of methodological tools to support } \\
\text { designers and generate systemic solutions including } \\
\text { products and services. }\end{array}$ & Morelli 2002, 2006. \\
\hline
\end{tabular}


Table 2 Service definition variations through two approaches

\begin{tabular}{|c|c|c|}
\hline Characteristics & Traditional Approach & Broader Approach \\
\hline Primary objective & $\begin{array}{l}\text { Functionally available product. Fit for } \\
\text { use. }\end{array}$ & Satisfaction of customer value. \\
\hline Applicability & Matured product & Initial stages of development \\
\hline Properties & $\begin{array}{c}\text { Intangible, heterogeneous, inseparable, } \\
\text { perishable, realized and consumed } \\
\text { simultaneously }\end{array}$ & $\begin{array}{l}\text { Derived from customer value. Yet to } \\
\text { define concretely. }\end{array}$ \\
\hline Stakeholders Involvement & $\begin{array}{l}\text { Co-operation in terms of information } \\
\text { transfer and usage analyses. }\end{array}$ & $\begin{array}{l}\text { Co-creation should be considered } \\
\text { primarily. }\end{array}$ \\
\hline Degree of freedom & $\begin{array}{l}\text { Restricted and focused to operational } \\
\text { factors. }\end{array}$ & $\begin{array}{l}\text { Wider scope with opportunities to } \\
\text { substitute between tangible and } \\
\text { intangible objects. }\end{array}$ \\
\hline Evaluation criteria & $\begin{array}{l}\text { Uptime, failure rate and severity of } \\
\text { failures }\end{array}$ & User experiences and expectations. \\
\hline
\end{tabular}


Figure 1 Elements involved in the PSS

Figure 2 The architecture of Service CAD (Komoto and Tomiyama, 2009)

Figure 3 Relations between the sub-models: flow, scope, scenario and view models (Sakao et al. 2009) Figure 4 Integrated product and service design processes (Aurich et al. 2006)

Figure 5 Structure of the extended heterogeneous IPS 2 concept modelling approach (Welp et al. 2008)

Figure 6 PSS Design (Maussang et al. 2009)

Figure 7 Fast-track design process stages (Alonso-Rasgado et al. 2004)

Figure 8 The design process for the development of services (Morelli, 2002)

Figure 9 The four PSS dimensions and design process (Tan et al. 2009)

Figure 10 Relative maturity of various issues considered in PSS domain 